\title{
The Morphology of Eyewall Lightning Outbreaks in Two Category 5 Hurricanes*
}

\author{
K. SQUiRES ${ }^{+}$AND S. BUSINGER \\ University of Hawaii at Manoa, Honolulu, Hawaii
}

(Manuscript received 25 January 2007, in final form 6 July 2007)

\begin{abstract}
Data from the Long-Range Lightning Detection Network (LLDN), the Tropical Rainfall Measuring Mission (TRMM) satellite, and reconnaissance aircraft are used to analyze the morphology of lightning outbreaks in the eyewalls of Hurricanes Rita and Katrina, two of the strongest storms in the Atlantic hurricane record. Each hurricane produced eyewall lightning outbreaks during the period of most rapid intensification, during eyewall replacement cycles, and during the time period that encompassed the maximum intensity for each storm.

Within the effective range of the aircraft radar, maxima in eyewall strike density were collocated with maxima in radar reflectivity. High lightning strike rates were also consistently associated with TRMM low brightness temperatures and large precipitation ice concentration (PIC) values. The strike density ratio between the eyewall region and the outer rainband region was $6: 1$ for Hurricane Rita and 1:1 for Hurricane Katrina. This result is in contrast to those of previous remote lightning studies, which found that outer rainbands dominated the lightning distribution. The differences are shown to be at least in part the result of the more limited range of the National Lightning Detection Network (NLDN) data used in the earlier studies. Finally, implications of the results for the use of LLDN lightning data to remotely examine changes in hurricane intensity and structural evolution are discussed.
\end{abstract}

\section{Introduction}

It has been shown that the convective structure of the eyewall of a mature hurricane can provide valuable information about changes in storm intensity (Jorgensen 1984; Black and Hallett 1986; Black et al. 1994; Marks 1985; Heymsfield et al. 2001). Marks (1985) showed that intensification of a hurricane could be represented by a contraction of the eyewall, as well as by an increase in the strength of the convection within the eyewall. Black et al. (1994) also document a strengthening and deepening of the convection contained within the eyewall of Hurricane Emily (1987) as the hurricane intensified. Heymsfield et al. (2001) showed that the devel-

\footnotetext{
* School of Ocean and Earth Science and Technology Contribution Number 7313 .

+ Current affiliation: NOAA/National Weather Service, Central Weather Service Unit, Ronkonkoma, New York.
}

Corresponding author address: S. Businger, Department of Meteorology, University of Hawaii at Manoa, 2525 Correa Rd., Honolulu, HI 96822.

E-mail: businger@hawaii.edu opment of individual mesoscale convective systems contained within the eyewall of a mature hurricane could accompany significant intensity changes. Thus, it is of general interest to hurricane forecasters and researchers to develop methods that allow a continuous examination of the structural evolution of the eyewall within hurricanes.

The lightning strike rates produced by a convective system are positively correlated with the convective strength of that system (Orville and Vonnegut 1974; Orville et al. 1983; Williams et al. 1992). Orville and Vonnegut (1974) examined scanned photographs of lightning flashes, provided by Defense Meteorological Satellite Program (DMSP) satellites, which included both intracloud lightning flashes and cloud-to-ground strikes, in order to derive the lightning flash frequencies of specific convective systems. Orville et al. (1983) and Williams et al. (1992) both used a network of directionfinding sensors that detected cloud-to-ground lightning strikes produced by convective systems. Williams et al. (1992) also analyzed the individual convective systems using vertical reflectivity profiles provided by a groundbased radar, concluding that as convective systems become more vigorous, their cloud-to-ground strike rates increase. The results of these various studies suggest 
that it is possible to infer information about the development and evolution of a convective system by observing its lightning strike morphology. It should be noted that the dynamics of a mature hurricane eyewall will differ from that of isolated convective storms.

Molinari et al. $(1994,1999)$ investigated lightning in hurricanes through the use of remote cloud-to-ground lightning detection data collected by the National Lightning Detection Network (NLDN). Their studies looked for links between eyewall structure, inferred from the remote lightning data, and changes in storm intensity. Molinari et al. (1999, hereafter MMI) used NLDN lightning data to examine the hourly lightning evolution in nine Atlantic hurricanes, three of which were previously studied by Lyons and Keen (1994). They concluded that mature tropical cyclones (TC) could be divided into three regions with respect to the density of cloud-to-ground lightning strikes (i.e., the number of measured strikes per unit area per time). Segmenting each storm into $20-\mathrm{km}$ radial bins, MMI found that the greatest strike density was contained in the outer rainband region, outward of $\sim 140 \mathrm{~km}$ from the storm center. A secondary maximum was located in the eyewall region, $0-60 \mathrm{~km}$ from the storm center, which was approximately 2-6 times less than that observed in the outer rainband region. A minimum in strike density was found in the inner rainband region, $\sim 80-100 \mathrm{~km}$ outward from the eyewall maximum. These three regions, defined by lightning strike density in MMI, are comparable with the three convective regions of a mature TC described by Jorgensen (1984); in particular, (i) the eyewall region, an area of outwardsloped convection that surrounds the eye and contains moderate vertical velocities (approximately $4-6 \mathrm{~m} \mathrm{~s}^{-1}$ ); (ii) the stratiform region, which is located just outward of the eyewall and contains little active convection and weak vertical velocities; and (iii) the rainband region, which is characterized by the variable nature of the reflectivity and vertical velocity profiles.

In a study of 35 Atlantic basin tropical cyclones from 1985-99, Corbosiero and Molinari (2002) and Corbosiero (2003) found that $>90 \%$ of the NLDNdetected flashes in the storm core (defined as the inner $100 \mathrm{~km}$ ) occurred downshear when the magnitude of the 850-200-hPa vertical shear exceeded $5 \mathrm{~m} \mathrm{~s}^{-1}$. Moreover, they found that flashes most often occurred in the front half of the storm core, with a preference for the right-front quadrant. This storm-motion effect was attributed to the influence of asymmetric friction in the tropical cyclone boundary layer.

The lightning detection efficiency of the NLDN is sensitive to the distance of a lightning strike from the network sensors; as the distance increases the detection efficiency decreases sharply. As a result, previous researchers using NLDN data limited their analysis of lightning data to occasions when TCs centers were within $400 \mathrm{~km}$ of at least two direction-finding (DF) sensors (e.g., Molinari et al. 1994, 1999; Samsury and Orville 1994).

Cecil and Zipser (1999) conducted a study of dozens of TCs using lightning data provided by the Optical Transient Detector (OTD). Cecil et al. (2002a,b) used the Tropical Rainfall Measuring Mission (TRMM) satellite mounted Lightning Imaging Sensor (LIS) to study 261 TRMM satellite overpasses of 45 TCs. The OTD and LIS instruments operate with a detection efficiency of $60 \%$ and $90 \%$, respectively, and detect flashes from both intracloud lightning as well as cloud-to-ground strikes. Cecil et al. (2002a,b) found a radial distribution similar to MMI, in which there were lightning flash density maxima in the eyewall and outer rainband regions, with a distinct flash density minima located within the inner rainband region. However, Cecil and Zipser (1999) and Cecil et al. (2002a,b) found that the ratio of flash densities between the eyewall and outer rainband regions was closer to 1:1, not 1:2-6 as found by MMI. They also found there to be a greater likelihood of eyewall lightning in strong TCs, those with maximum sustained wind speeds $>49 \mathrm{~m} \mathrm{~s}^{-1}$. In addition, they noted that the flash densities produced within the eyewall were at least an order of magnitude smaller than those produced by continental thunderstorms.

Black and Hallett (1999) examined the electrification and hydrometeor characteristics within Hurricane Claudette (1991) and Hurricane Tina (1992) using an array of field mills mounted on a WP-3D aircraft. As the aircraft penetrated through the TCs, the field mill array was able to measure the strength and the polarity of the electric field at that particular flight level. Relatively low flash densities observed within the eyewall of mature hurricanes were consistent with the presence of relatively weak electric fields measured within the eyewall. The strongest vertical electric fields within the eyewall measured $\sim 17-24 \mathrm{kV} \mathrm{m}^{-1}$, which is approximately 3-5 times weaker than those measured in continental thunderstorms (Marshall and Rust 1991; Marshall et al. 1995).

The peaks in the electric field within the eyewall were collocated with the strongest updraft velocities and highest supercooled water concentrations. Black and Hallett (1999) concluded that the large amount of ice produced within the eyewall of a mature hurricane acts to nucleate and freeze much of the liquid water content (LWC) that is present above the $0^{\circ} \mathrm{C}$ isotherm. This process, along with relatively modest vertical velocities, results in few supercooled water droplets 
within the eyewall, which-in conjunction with precipitation ice particles-are needed for charge separation within clouds (Ziv and Levin 1974; Takahashi 1978; Beard and Ochs 1986; Saunders et al. 1991; Saunders 1995). Therefore, Black and Hallett (1999) suggest that lightning outbreaks within the eyewall should be rare, especially when compared to continental convection. Observations of limited convective available potential energy (CAPE) and enhanced vertical velocities in the eyewall of mature hurricanes tend to support this notion (Gray 1965; Jorgensen et al. 1985; Emanuel 1986; Bogner et al. 2000).

In this study, data from the Long-Range Lightning Detection Network (LLDN) are compared with convective precipitation and precipitable ice derived from aircraft radar and TRMM data in the eyewall regions of two category 5 hurricanes. The overarching goal of this work is to demonstrate the promise of continuous LLDN data to remotely infer the evolution of the convective structure of hurricane eyewalls.

\section{Data and methods}

The lightning data used in this study were obtained from the archives of the LLDN operated by the Vaisala Thunderstorm Group (Cummins et al. 1998, 1999; Cramer and Cummins 1999; Demetriades and Holle 2005, 2006). First implemented in 1996, the LLDN initially included only the sensors in the U.S. NLDN (Orville et al. 2002). In 1998, the coverage, detection efficiency, and location accuracy were all improved with the addition of sensor information from the Canadian Lightning Detection Network (CLDN). At the time of the two hurricanes used in this study (2005), the LLDN comprised 187 sensors.

The LLDN detects very low-frequency (VLF) electromagnetic waves reflected from the ionosphere to determine lightning strike locations. The range of the LLDN data used in this study is an order of magnitude greater than that of the NLDN data used in previous hurricane studies, allowing for a more complete documentation of the lightning evolution in Hurricanes Rita and Katrina. However, since the polarity of the signal is reversed with each ionospheric reflection, it is not possible to determine the strike polarity with this method of detection. The network is unreliable in a small region just north of Cuba, where linear bands of false strikes appear. These linear patterns, caused by the geometry of the network in Florida, were also observed in previous lightning studies (see Molinari et al. 1994, 1999) and are explained in more detail in MMI.

The detection efficiency of the LLDN data over the Gulf of Mexico has been extensively evaluated using
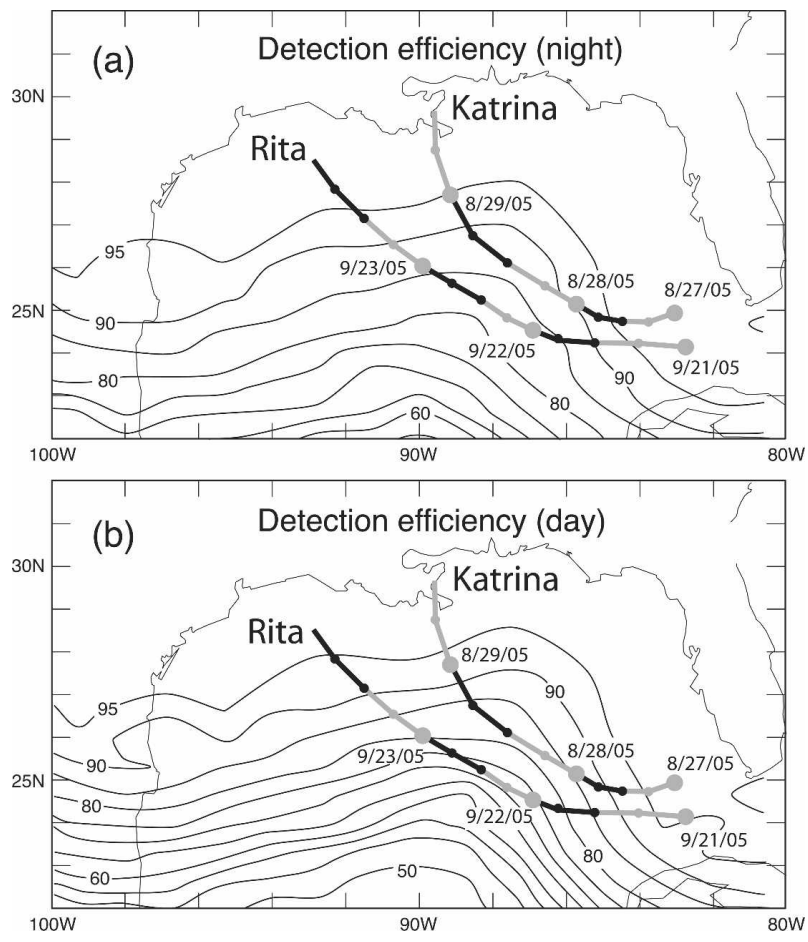

FIG. 1. Detection efficiency (\%) for the Gulf of Mexico region during (a) nighttime and (b) daytime. Hourly storm tracks for both Hurricanes Rita and Katrina are displayed using hourly interpolations of best-track 6-h data obtained from NHC. Storm tracks during times of local day (night) are represented by the bold black (gray) line segments.

data from LIS and NLDN. The detection efficiency of the LLDN depends on the strike strength, its distance from the network, and the time of day (K. Cummins 2006, personal communication) (Fig. 1). Strong strikes (greater than 30-kA peak current) and strikes that are close to the network are detected more efficiently. A diurnal variation in detection efficiency is a result of the VLF detection method and ionospheric propagation conditions, with the detection efficiency being greater during nighttime hours. Given the tracks of Hurricanes Rita and Katrina, the detection efficiency values ranged from approximately $75 \%$ to $95 \%$ (Fig. 1). This study does not explicitly account for variations in detection efficiency. In objective applications of lightning data, such as data assimilation into numerical weather prediction models, the variations in detection efficiency need to be taken into account. For this purpose modeled detection efficiency can be used. Although LIS represents an independent remote sensing strategy for detecting lightning, the short viewing window ( $99 \mathrm{~s})$ over a particular region resulted in relatively little data for the storms studied here and were not explicitly included in this study.

Cramer and Cummins (1999) conducted a location 
accuracy study within the NLDN, using both NLDN and LLDN detection methods. They concluded that median location accuracy of the LLDN detected strikes is $\sim 5 \mathrm{~km}$. The vertical sections of lightning bolts provide the strongest signal for the NLDN and LLDN to detect. The orientation of the lowest few kilometers of a strike is often vertical, whereas the higher portions of the lightning channel may be more horizontal in orientation. Therefore, the median lateral displacement of each strike from its cloud origin is not exactly known, but will likely fall within the radius of the median displacement accuracy.

Lightning strike counts in this paper are normalized per $100 \mathrm{~km} \times 100 \mathrm{~km}$ or $(100 \mathrm{~km})^{-2}$ and referred to as lightning strike density. Lightning density data were divided hourly into $25-\mathrm{km}$ annular rings beginning at the storm center and continuing outward to $300 \mathrm{~km}$. Following Molinari et al. $(1994,1999)$, the radial bins were grouped into three regions, the eyewall $(0-50 \mathrm{~km})$, the inner rainband $(75-175 \mathrm{~km})$, and the outer rainband $(r>175 \mathrm{~km})$.

The TRMM Microwave Imager (TMI) is a passive radiometer sensor that receives radiation in five wavelengths. Vertically polarized $85-\mathrm{GHz}$ brightness temperatures measured by the TMI are used in this study and have an effective footprint of approximately $5 \times 7$ $\mathrm{km}$ (TRMM product 1B11). Also, the hydrometeor profile product is used to estimate the horizontal and vertical distribution of precipitation-sized ice (details on algorithm 2A12 are available online at http:// disc.sci.gsfc.nasa.gov). The algorithm generates vertical profiles of hydrometeors for 14 levels by combining TMI brightness temperature data with dynamical cloud models. For the vertically polarized $85-\mathrm{GHz}$ channel and the hydrometeor profiler, the scan width is $878 \mathrm{~km}$ and the ground resolution is $5 \mathrm{~km}$.

Passive microwave brightness temperatures at 85 $\mathrm{GHz}$ have been used in various studies to determine the vertical development and related strength of convective systems (e.g., Mohr et al. 1999; Cecil and Zipser 1999; Nesbitt et al. 2000; Cecil et al. 2002a,b; Lee et al. 2002). The $85-\mathrm{GHz}$ channel brightness temperature is sensitive to radiation scattering by submillimeter and largersized precipitation ice particles. The brightness temperature decreases with deeper vertical distribution, increasing particle size, and increasing concentration of these hydrometeors. Within the tropics the frequency of lightning flashes for convective systems increases as their respective $85-\mathrm{GHz}$ temperatures decrease (Nesbitt et al. 2000; Cecil et al. 2002a,b).

The TMI hydrometeor profile product, which is based in part on the Kummerow et al. (2001) Goddard profiling algorithm (GPROF) algorithm, allows precipitation-sized ice concentrations $\left(\mathrm{g} \mathrm{m}^{-3}\right)$ to be estimated at various vertical layers. A careful calibration of the precipitation ice concentration (PIC) product is unavailable; therefore, comparisons and inferences based on PIC values in this paper are qualitative in nature.

After examining all vertical levels above $5 \mathrm{~km}$, it was determined that level 12 (corresponding to an elevation range of 8-10 km above sea level) showed the greatest contrast between images taken during times of high strike density and images taken with little or no lightning present. When comparing images from different times, as well as comparing different areas within the same image, stronger convection is associated with greater PIC. Enhanced vertical velocities within the area of active convection lift ice particles higher into the atmosphere, consistent with the observation that the greatest contrast occurs at level 12. Similar contrasts were also seen at level $10(5-6 \mathrm{~km})$ and level $11(6-8$ $\mathrm{km})$, however, they were less pronounced than those at level 12. A study by Fiorino and Smith (2006) examined the accuracy of the TRMM PIC product by comparing TRMM-derived PIC values with in situ aircraft PIC measurements and found that the level-12 TRMM PIC product tended to underestimate actual values by $\sim 20 \%$. The lower-level values of TRMM-derived PIC found in Hurricanes Rita and Katrina are similar to the values derived from in situ radar data in the hurricane studies by Black (1990) and Gamache et al. (1993).

The flight-level and radar data were collected by the National Oceanic and Atmospheric Administration (NOAA) WP-3D aircraft during numerous flight missions through both hurricanes and were made available for this study by the Hurricane Research Division (HRD). The environmental variables used in this study include aircraft location and vertical and horizontal wind speed. These parameters are measured along the aircraft flight path with a sampling rate of $1 \mathrm{~Hz}$. Horizontal and vertical reflectivity distributions were obtained by the lower fuselage radar $(5.59-\mathrm{cm}$ wavelength) and the tail-mounted radar $(3.22-\mathrm{cm}$ wavelength). Analysis of the radar reflectivity data revealed that there was a discrepancy in the strength of the radar returns that point to a potential problem with radar calibration or frequency drift (J. Gamache 2006, personal communication). Nevertheless, relative reflectivity values and patterns within individual scans can be used to infer qualitative relationships.

The vertical reflectivity profiles used in this study are storm-relative composite images that comprise $\sim 20-30$ min of tail-mounted radar data gathered during radial eyewall penetrations by the WP-3D aircraft. For all 
plan position indicator (PPI) images lightning strike locations are overlaid throughout the entire image. In deference to the increasing effects of attenuation and inadequate beam filling at large range, a $70-\mathrm{km}$ range ring demarcating the nominal effective range of the lower fuselage radar is added to each aircraft PPI radar image (Marks 1985).

The Geostationary Operational Environmental Satellite (GOES-12) satellite area files were obtained from the National Environmental Satellite, Data, and Information Service (NESDIS). The files were processed into standard 4-km resolution infrared images using the Man computer Interactive Data Access System (McIDAS-X) imaging software. Lightning data were then overlaid onto the satellite images using the same software.

\section{Results}

Hurricanes Rita and Katrina were two of the most intense hurricanes in the historical record of Atlantic and Gulf of Mexico hurricanes, attaining minimum central pressures of 895 and $902 \mathrm{mb}$, respectively (Knabb et al. 2005, 2006). Rita and Katrina were also similar storms in terms of genesis region, track, and mature lifetime. Each hurricane produced eyewall lightning outbreaks during the period of most rapid intensification (RI), during eyewall replacement cycles (ER), and during the time period that encompassed the maximum intensity (MI) for each storm.

In this paper only the three best-sampled eyewall lightning outbreaks are discussed; the RI and ER eyewall outbreaks in Hurricane Rita, and the MI eyewall lightning outbreak that occurred in Hurricane Katrina. Outbreaks lacking ancillary data from either the NOAA P-3 aircraft or the TRMM satellite are not included in this paper. For a detailed discussion encompassing all of the eyewall lightning outbreaks for each storm please refer to Squires (2006).

\section{a. Rita}

The strike density of cloud-to-ground lightning produced within the eyewall of Hurricane Rita exceeds any reported in previous studies using NLDN or LLDN in the core region of a hurricane. Lightning data for Hurricane Rita began at 0000 UTC 21 September and ended just prior to landfall at 2300 UTC 23 September. Data collected prior to 0000 UTC 21 September were not included in this study, because of detection errors associated with the geometry of the LLDN over Florida (MMI).

The strike density maximum for Hurricane Rita was

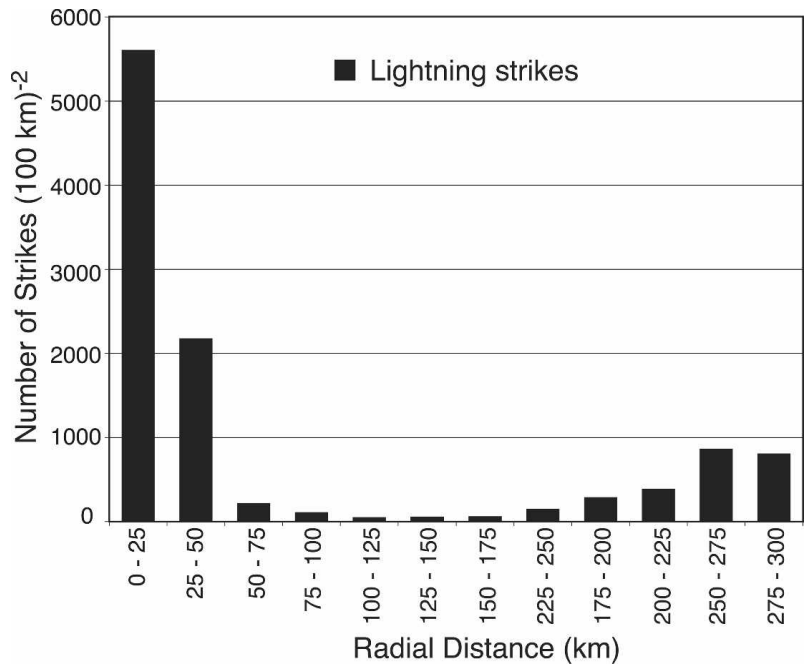

FIG. 2. Radial distribution of the total number of lightning strikes for Hurricane Rita between 0000 UTC 21 Sep and 2300 UTC 23 Sep.

contained within the eyewall region, not in the outer rainband region (Fig. 2). The $0-25-\mathrm{km}$ bin of Rita contained a total of 5608 strikes $(100 \mathrm{~km})^{-2}$ over the $71-\mathrm{h}$ period, which is $\sim 7$ times larger than any one of the outer rainband bins. During the same period the eyewall region $(0-50 \mathrm{~km})$ of Hurricane Rita produced an average of 986 strikes $(100 \mathrm{~km})^{-2}$ day $^{-1}$ (Fig. 2). For comparison, Hurricane Andrew (1991), the strongest hurricane examined by Molinari et al. (1994), produced only 54 strikes $(100 \mathrm{~km})^{-2}$ day $^{-1}$ in the eyewall region $(0-40 \mathrm{~km})$. In a global sense the flash densities produced by Hurricane Rita's outbreaks are significant when compared to lightning rates typical of deep tropical convection (Zipser and LeMone 1980; Zipser 1994); however, they are modest when compared to landbased convective storms, which sometimes contain flash rates exceeding 100 flashes per minute, over areas $<(100 \mathrm{~km})^{2}$ (Cecil et al. 2005; Zipser et al. 2006).

Three eyewall outbreaks occurred during the $71-\mathrm{h}$ period beginning at 0000 UTC 21 September 2005 (Fig. 3 ). The first outbreak reached a maximum at 1600 UTC 21 September, a period of rapid intensification (RI outbreak), during which the maximum sustained winds increased $34 \mathrm{~m} \mathrm{~s}^{-1}$ in $24 \mathrm{~h}$ and the central pressure dropped $68 \mathrm{mb}$ in $22.5 \mathrm{~h}$. A second outbreak occurred at the end of the period of rapid intensification, between 2300 UTC 21 September and 0700 UTC 22 September, during the time Rita reached maximum intensity (MI outbreak). A final outbreak at 1800 UTC on 22 September was much smaller than the first two both in intensity and duration and was associated with an eyewall replacement cycle (ER outbreak). For the remain- 


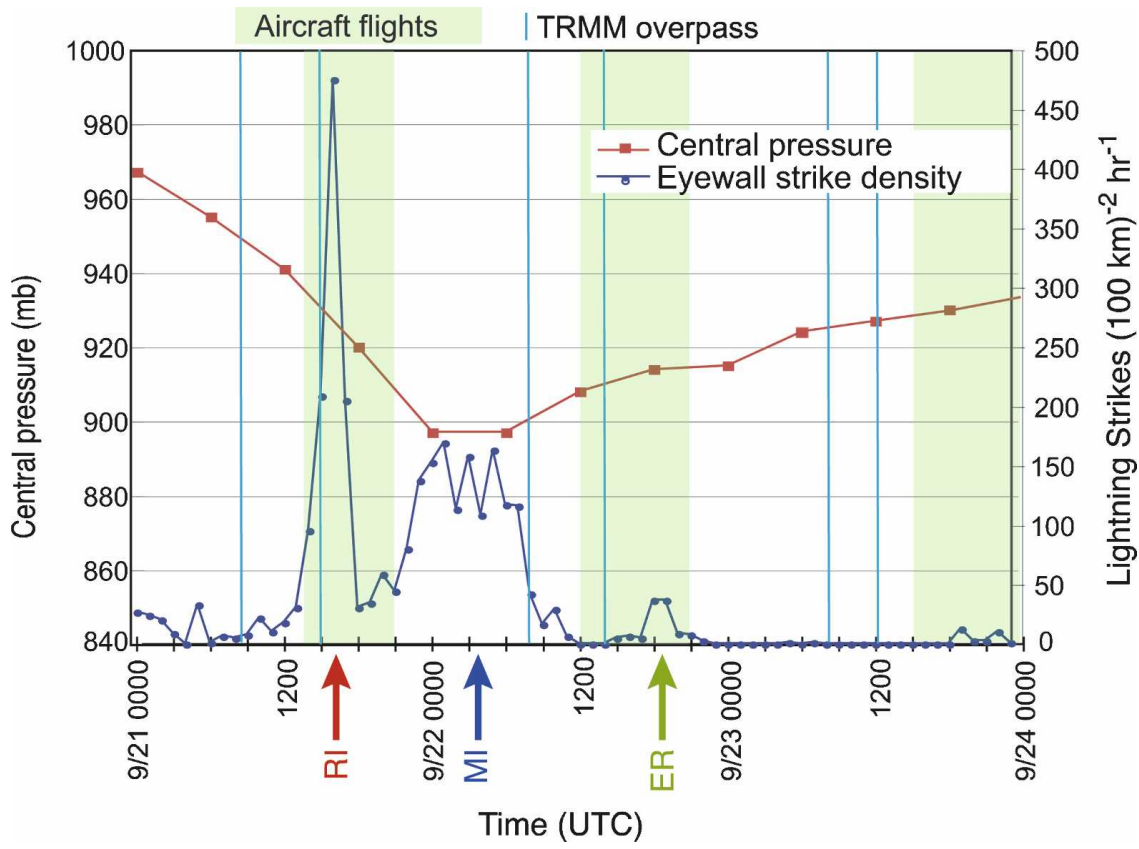

FIG. 3. Time series containing the hourly cloud-to-ground strike density within $50 \mathrm{~km}$ of the center of Hurricane Rita (blue line). Strike totals are normalized by the number of strikes in $(100 \mathrm{~km})^{-2} \mathrm{~h}^{-1}$. The red line shows linear interpolations of the storm's central pressure from the NHC best-track 6-h data. Times when TRMM data (blue line) and aircraft data (green shading) were available are indicated. Eyewall lightning outbreaks identified by labeled arrows include RI, MI, and ER.

der of this section we will discuss the RI and ER eyewall lightning outbreaks that were best sampled by aircraft and TRMM instruments.

The RI outbreak contained the highest strike rate in this study, producing a maximum hourly strike density of 474 strikes $(100 \mathrm{~km})^{-2} \mathrm{~h}^{-1}$. The outbreak began at $1400 \mathrm{UTC}, 10 \mathrm{~h}$ after the TC begun to rapidly intensify, and lasted $\sim 5 \mathrm{~h}$. The eye had begun contracting earlier in the day (Knabb et al. 2005) and at the time of the RI outbreak reduced to $\sim 40 \mathrm{~km}$ in diameter (Fig. 4).

Aircraft-measured reflectivity during the RI outbreak shows that the eye was completely enclosed by a relatively axisymmetric wall of surrounding convection (Fig. 4). However, reflectivity values varied slightly around the eyewall, with the northwest and southeast sides containing the highest reflectivity values. During this outbreak lightning strikes were detected in every region of the eyewall. However, strike density maxima were located in the northwestern and southeastern regions of the eyewall, and within $\sim 5$-km radial distance of higher reflectivity values.

Vertical reflectivity profiles from the tail radar at various azimuths show a well-defined outward tilt of the eyewall (Fig. 5). At this time Hurricane Rita displayed relatively deep convection for a mature hurri- cane eyewall region, containing enhanced reflectivities above the melting level, with a gradual decrease of reflectivity with height. As noted in section 2, intercomparison of reflectivity values from various flights suggest that the values shown in Figs. 4 and 5 may be low as a result of a potential problem with radar calibration or frequency drift.

The absence of lightning outside of the eyewall region in the vertical reflectivity profiles is a feature Hurricane Rita shares with previously studied TCs (Molinari et al. 1994, 1999; Zipser and Lutz 1994). All of the vertical reflectivity profiles contain a region $50-90 \mathrm{~km}$ outward of the eyewall that is dominated by stratiform reflectivity represented by a brightband signature with reflectivity falling off quickly with height. This brightband layer outward of the eyewall is the result of frozen particles falling and melting in the presence of weak vertical updrafts (Szoke et al. 1986; Yuter and Houze 1995).

In contrast, flight-level updraft velocities in the eyewall are substantial, with maximum velocities measuring $>4.5 \mathrm{~m} \mathrm{~s}^{-1}$ for each eyewall penetration (Fig. 5). The northern eyewall pass recorded the strongest eyewall updraft for any radial pass for either storm, with a peak velocity of $16.5 \mathrm{~m} \mathrm{~s}^{-1}$. Within this updraft, vertical 


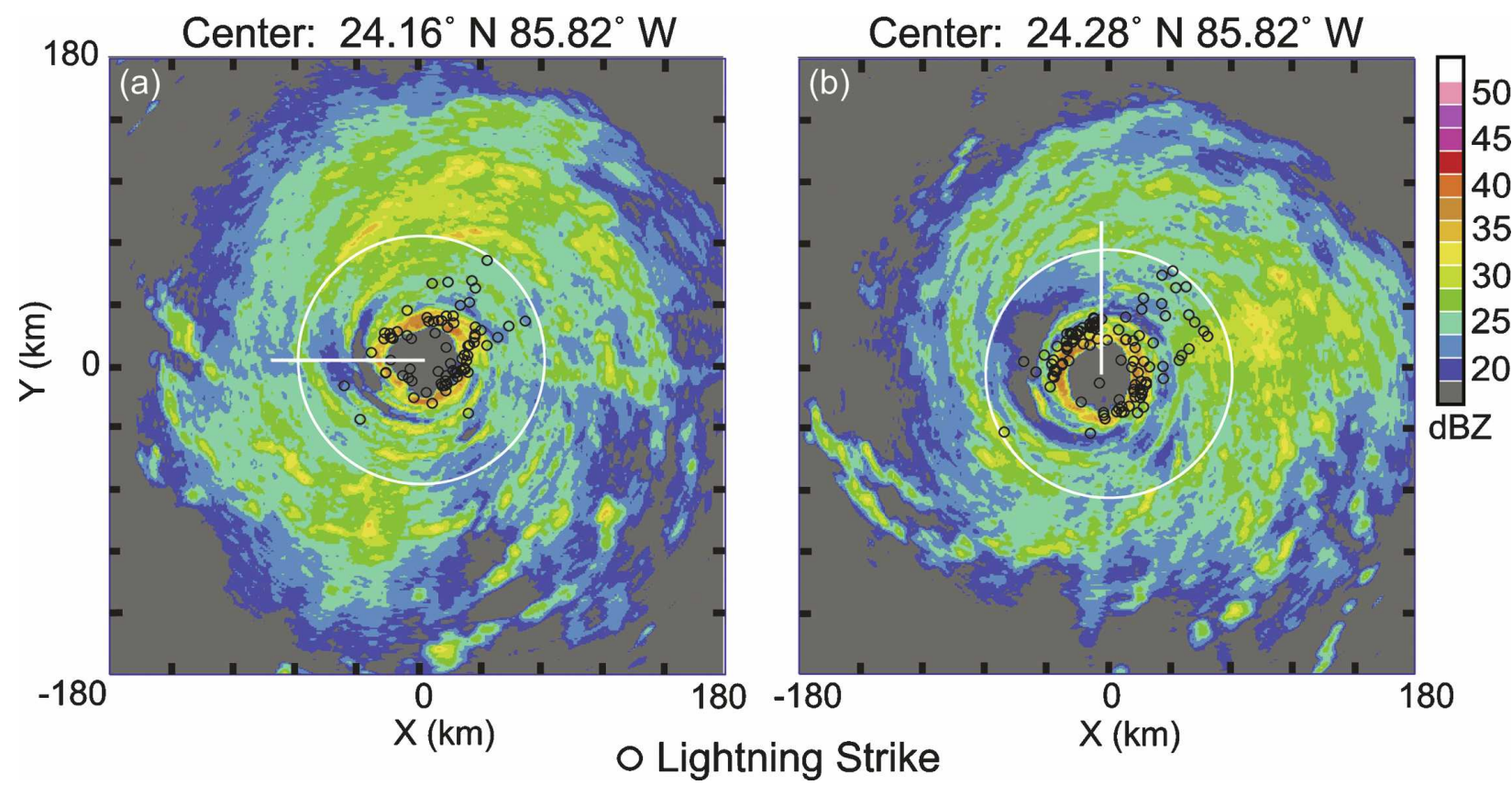

FIG. 4. NOAA WP-3D lower-fuselage radar reflectivity taken on $21 \mathrm{Sep}$ at an altitude of $2700 \mathrm{~m}$. The nominal effective range of the lower-fuselage radar is shown as a range ring at $70 \mathrm{~km}$ (white circle). Superimposed onto each image is $\pm 10 \mathrm{~min}$ of lightning data (black circles) centered on the time of the image. The white radial lines indicate the approximate locations of cross sections in Figs. 5b,d. Reflectivity at (a) 1523 and (b) 1602 UTC.

velocities $>7.5 \mathrm{~m} \mathrm{~s}^{-1}$ were observed over a distance of $2 \mathrm{~km}$ (Fig. 5d). This radial leg also contained the greatest number of lightning strikes, with 16 strikes detected in the range of $12-28 \mathrm{~km}$ from the center of Rita. These updraft velocities are consistent with the strongest vertical velocities reported by Jorgensen et al. (1985).

A TRMM satellite pass occurred just minutes prior to the time of the detected maximum eyewall strike rate (Fig. 6). More than 150 cloud-to-ground strikes were detected within the eyewall region from 1520 to 1550 UTC. During the same time the entire eyewall contained brightness temperatures $<200 \mathrm{~K}$, with $\sim 20 \%$ of the pixels $<150 \mathrm{~K}$ (Fig. 6a). Cecil et al. (2002a) found that fewer than $15 \%$ of hurricanes contain $85-\mathrm{GHz}$ temperatures $<150 \mathrm{~K}$ within the eyewall. The low brightness temperatures observed in Rita are consistent with the storm's symmetric organization and deepening central pressure during the time of the RI outbreak $(\sim 920$ mb in Fig. 3).

A lower strike density in the western region of the eyewall during this time coincided with slightly warmer brightness temperatures in that area. However, during this RI outbreak, no region of the eyewall was void of detected lightning strikes when viewed for periods on the order of $\sim 1 \mathrm{~h}$.

PIC reached a maximum of $>0.7 \mathrm{~g} \mathrm{~m}^{-3}$ in the eyewall, with values dropping quickly radially outward
(Figs. 5c and 6b). The maximum PIC occurred 4-5 km outward of aircraft-measured maximum radar reflectivity and vertical velocity (Fig. 5d). The outward displacement of the reflectivity maximum may be attributed to advection and the outward tilt of the eyewall with height. The eye is completely surrounded by PIC $>0.6 \mathrm{~g} \mathrm{~m}^{-3}$ in the $8-10-\mathrm{km}$ layer shown in Fig. $6 \mathrm{~b}$. The highest PIC observed $\left(>0.7 \mathrm{~g} \mathrm{~m}^{-3}\right)$ is in the northeastern region of the eyewall and corresponds to an area of enhanced strike density during the time of the image.

The next eyewall lightning outbreak in Hurricane Rita for which both aircraft and TRMM data were available was associated with an eyewall replacement cycle (ER outbreak in Fig. 3). This lightning outbreak continued from 1730 to 1930 UTC 22 September, with a maximum hourly strike density of 36 strikes $(100 \mathrm{~km})^{-2} \mathrm{~h}^{-1}$, and with nearly all of the lightning being detected within the decaying inner eyewall and not in the developing outer eyewall. The early stages of the developing outer eyewall are seen in Fig. 7 as the secondary band of low $85-\mathrm{GHz}$ brightness temperatures and maxima in PIC located $\sim 50-75 \mathrm{~km}$ from the center of Hurricane Rita. The convectively active region of the inner eyewall is associated with the minimum in brightness temperature and maximum in PIC located $\sim 25 \mathrm{~km}$ north of storm center. Although, Fig. 7 does not display any lightning strikes within the 20-min window cen- 


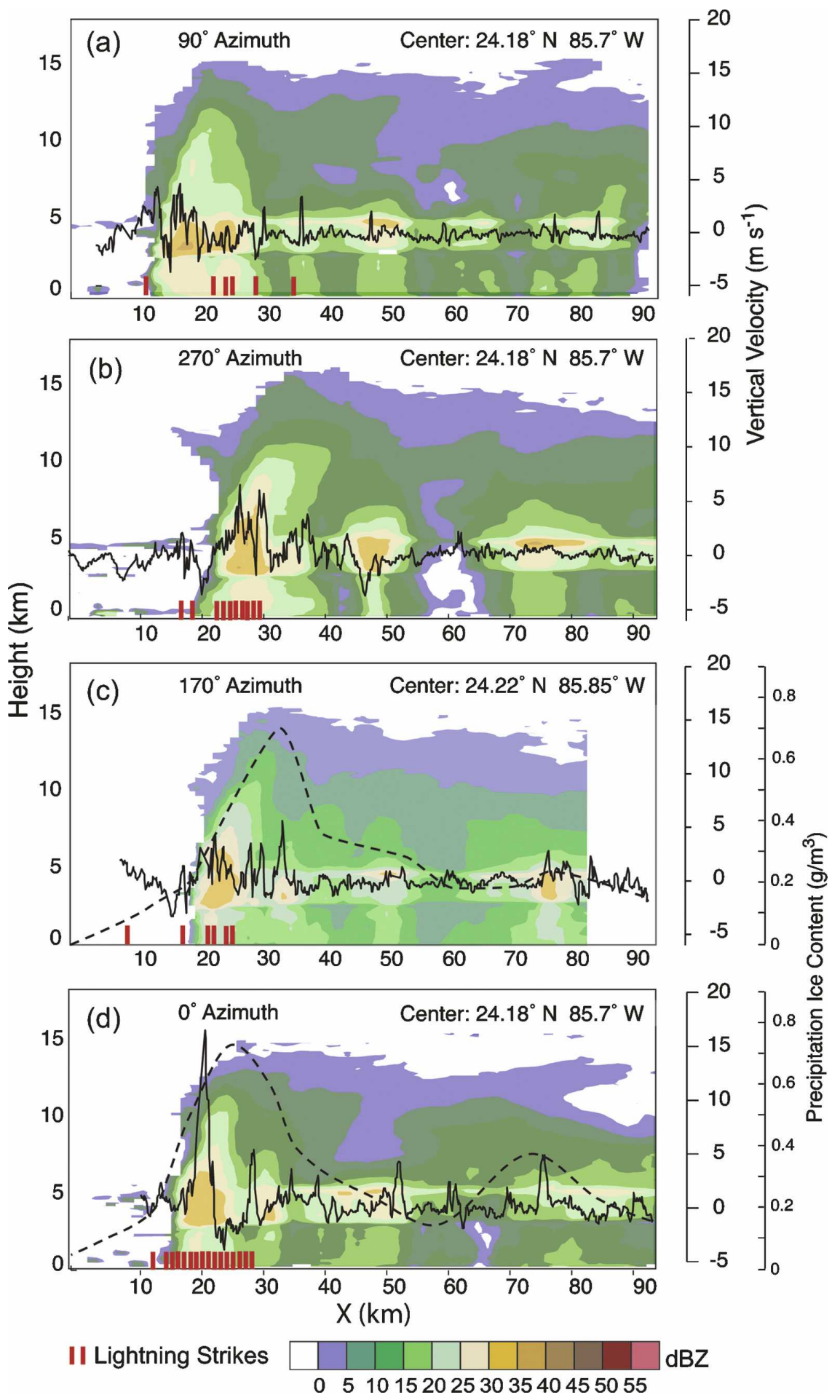

FIG. 5. Vertical reflectivity profile composites created by the NOAA WP-3D aircraft tail radar on $21 \mathrm{Sep}$, aircraft altitude ranges from 2600 to $2800 \mathrm{~m}$. Overlaid onto each cross section is flight-level vertical velocity measured along the corresponding flight path (solid line) and lightning strike locations (red bars) during the time of the radial section: (a) $90^{\circ}$ azimuth, 1506-1517 UTC; (b) $270^{\circ}$ azimuth, 1517-1535 UTC; (c) $170^{\circ}$ azimuth, 1550-1602 UTC; and (d) $0^{\circ}$ azimuth, 1602-1617 UTC. Radial distribution of level $12(8-10 \mathrm{~km})$ PIC values (dashed line) obtained at 1540 UTC 21 Sep fromTRMM data overlaid on (c) and (d). 

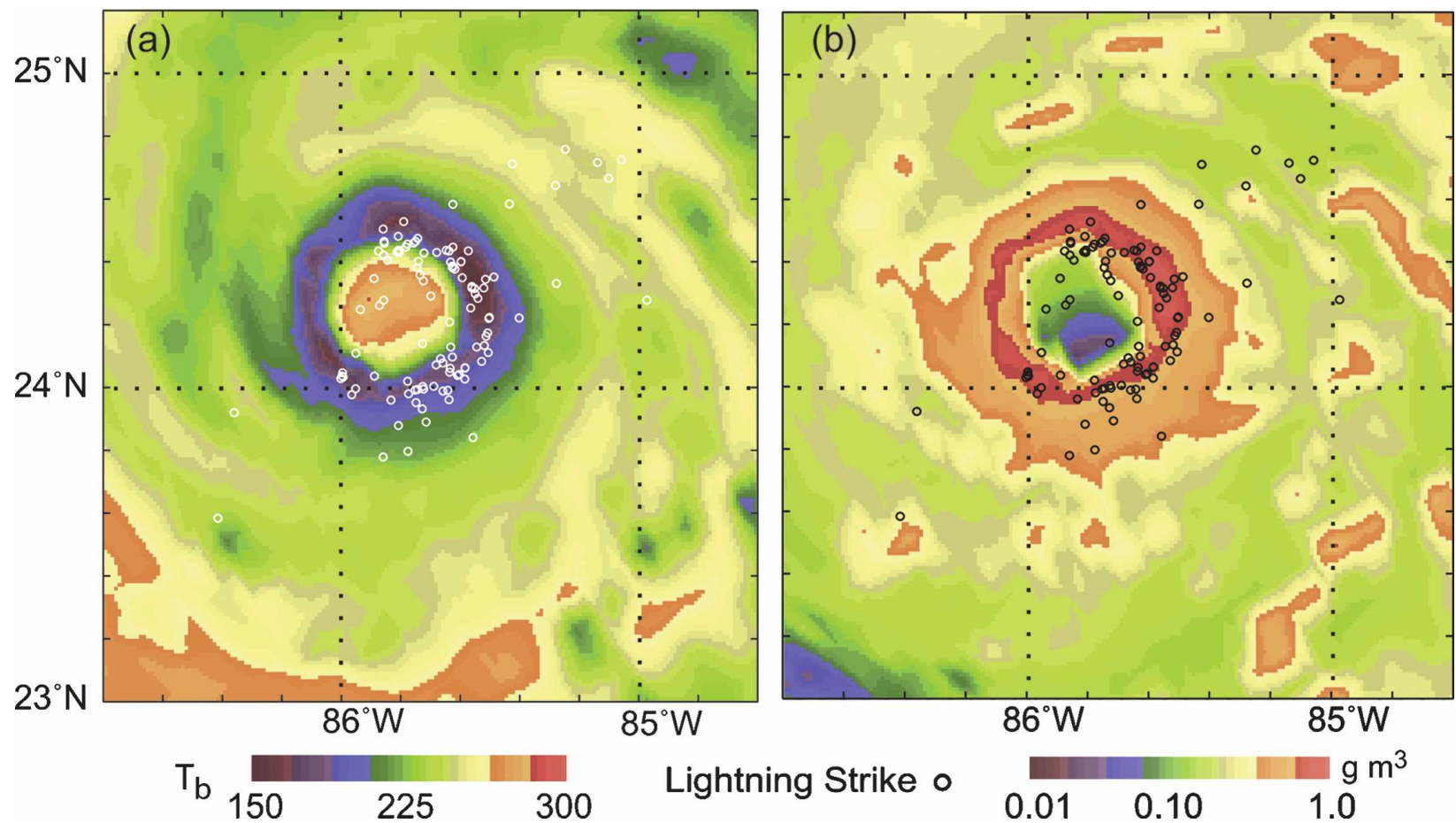

FIG. 6. TRMM data collected as the satellite passed over the center of Hurricane Rita at 1540 UTC, lightning strike locations (5-km circles are indicative of location accuracy) from 1530 to 1550 UTC 21 Sep: (a) 85-GHz TMI image with lightning (white circles) and (b) level $12(8-10 \mathrm{~km})$ PIC image with lightning (black circles).

tered on the time of the TRMM image, lightning strikes were detected in the inner eyewall region just north of Rita's center 30 min after the time of the image.

The outer eyewall gradually contracted on 22 September to form a ring of high radar reflectivity approximately $40-50 \mathrm{~km}$ from the center of Hurricane Rita (Figs. 8 and 9). During the time period 1730-1930 UTC, the inner eyewall strike density rose to 36 strikes (100 $\mathrm{km})^{-2} \mathrm{~h}^{-1}$. A large majority of detected strikes was within the northern region of the inner eyewall (Fig. 8). At this time, the reflectivity measured by aircraft radar within the northwestern half of the inner eyewall was relatively intense. This area of convection lasted for $>5 \mathrm{~h}$, and remained present in the final aircraft eyewall
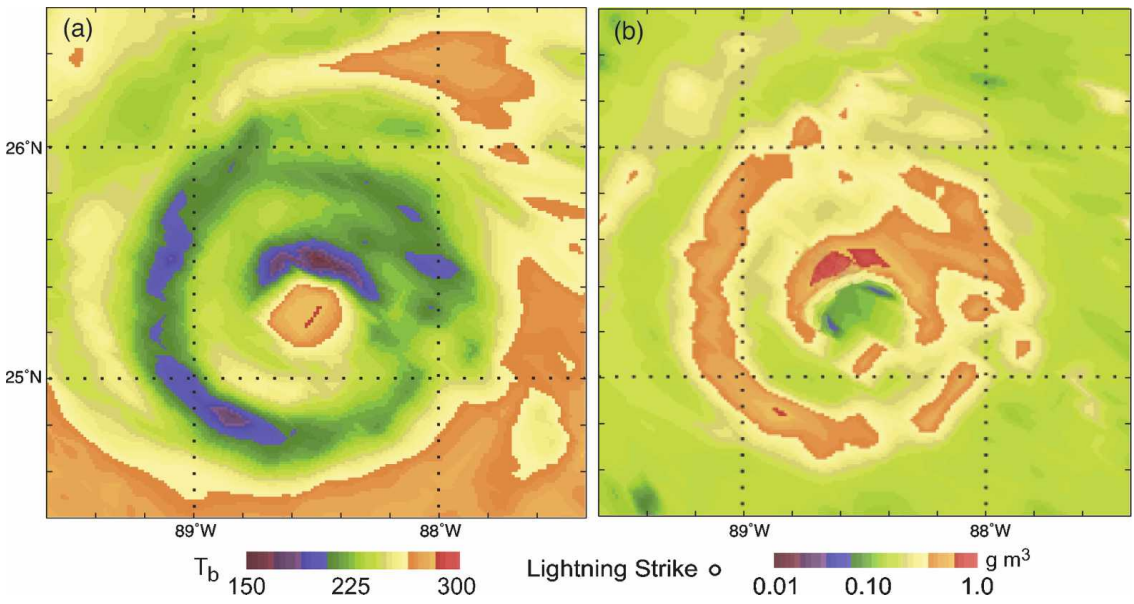

FIG. 7. Same as in Fig. 6, but with TRMM data for 1442 UTC 22 Sep. No cloud-to-ground lightning was detected $\pm 20 \mathrm{~min}$ from the time of the image: (a) $85-\mathrm{GHz}$ TMI and (b) level 12 $(8-10 \mathrm{~km})$ PIC. 

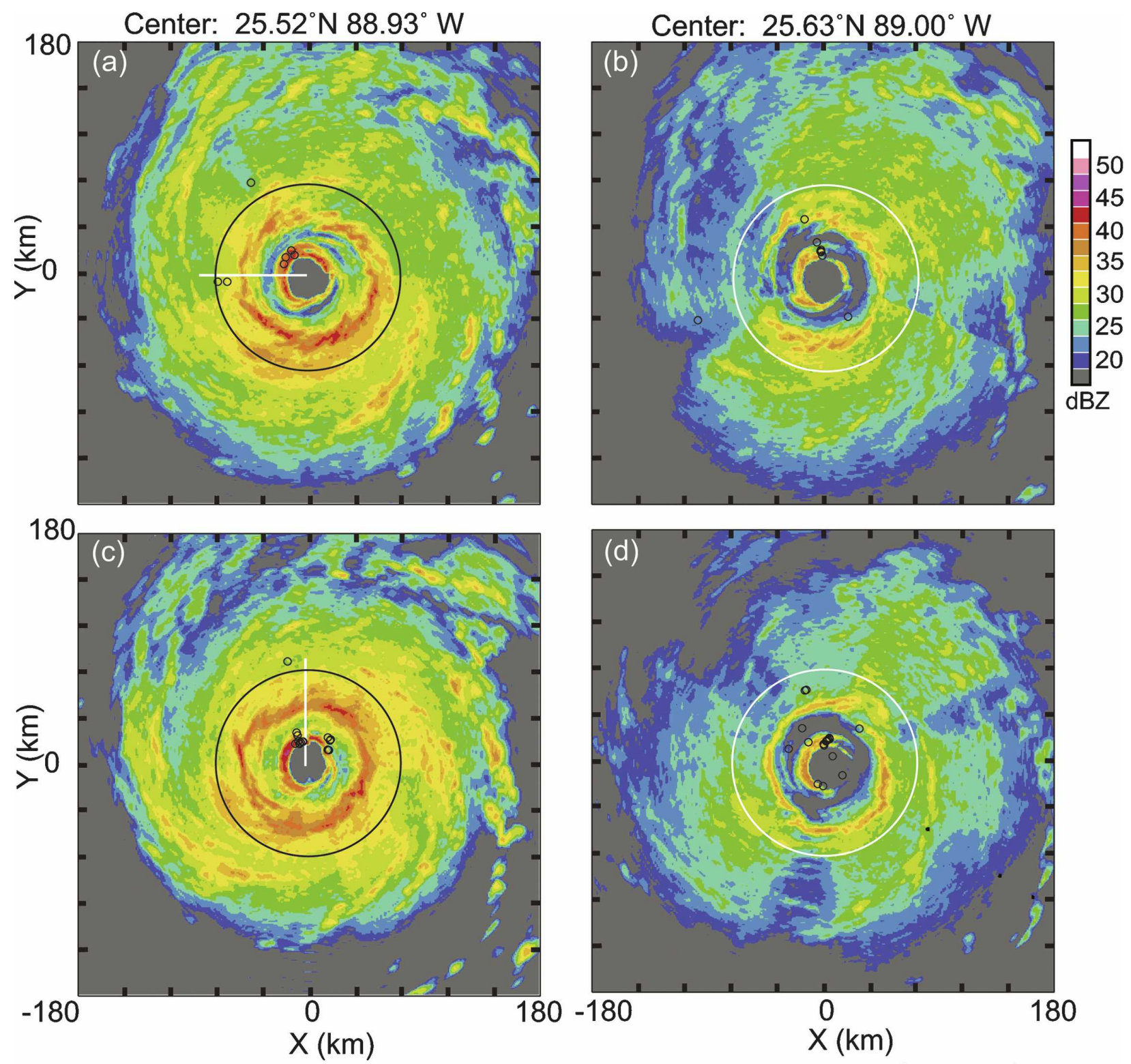

\section{Center: $25.62^{\circ} \mathrm{N} 89.07^{\circ} \mathrm{W} \quad \circ$ Lightning Strike Center: $25.62^{\circ} \mathrm{N} 89.03^{\circ} \mathrm{W}$}

FIG. 8. Same as in Fig. 4, but for reflectivity for (a) 1720 UTC 22 Sep at an altitude of $2100 \mathrm{~m}$, (b) 1751 UTC 22 Sep at an altitude of $2300 \mathrm{~m}$, (c) 1806 UTC $22 \mathrm{Sep}$ at an altitude of $1600 \mathrm{~m}$, and (d) 1912 UTC $22 \mathrm{Sep}$ at an altitude of $2300 \mathrm{~m}$. The white radial lines in (a) and (c) indicate the approximate locations of cross sections in Figs. 9a,b.

penetration at 2200 UTC 22 September. Both radial passes in Fig. 9 contain inner eyewall reflectivity values exceeding $30 \mathrm{~dB} Z$ into the mixed phase region. The northern eyewall pass shows $35-\mathrm{dB} Z$ reflectivity above $7 \mathrm{~km}$, and a maximum reflectivity value $>40 \mathrm{dBZ}$ around $2 \mathrm{~km}$ (Fig. 9b).

Although the ER lightning outbreak appeared to be associated with deeper convection than that sampled during the RI outbreak, the 1-h peak strike rate produced by this outbreak was only $8 \%$ of that produced by the rapid intensification outbreak. However, it is suggested that this discrepancy may be, in part, the result of a problem with the calibration of the radar as discussed in section 2 .

It may also be argued that advection by the storm's wind circulation away from areas of active convection, which are quasi-stationary relative to the storm center, acts to dilute charge. The tangential wind speed at PIC level $12(8-10 \mathrm{~km})$ in the eyewall (approximately $25-30 \mathrm{~km}$ from storm center) is $\sim 50 \mathrm{~m} \mathrm{~s}^{-1}$ (Fig. 10). 


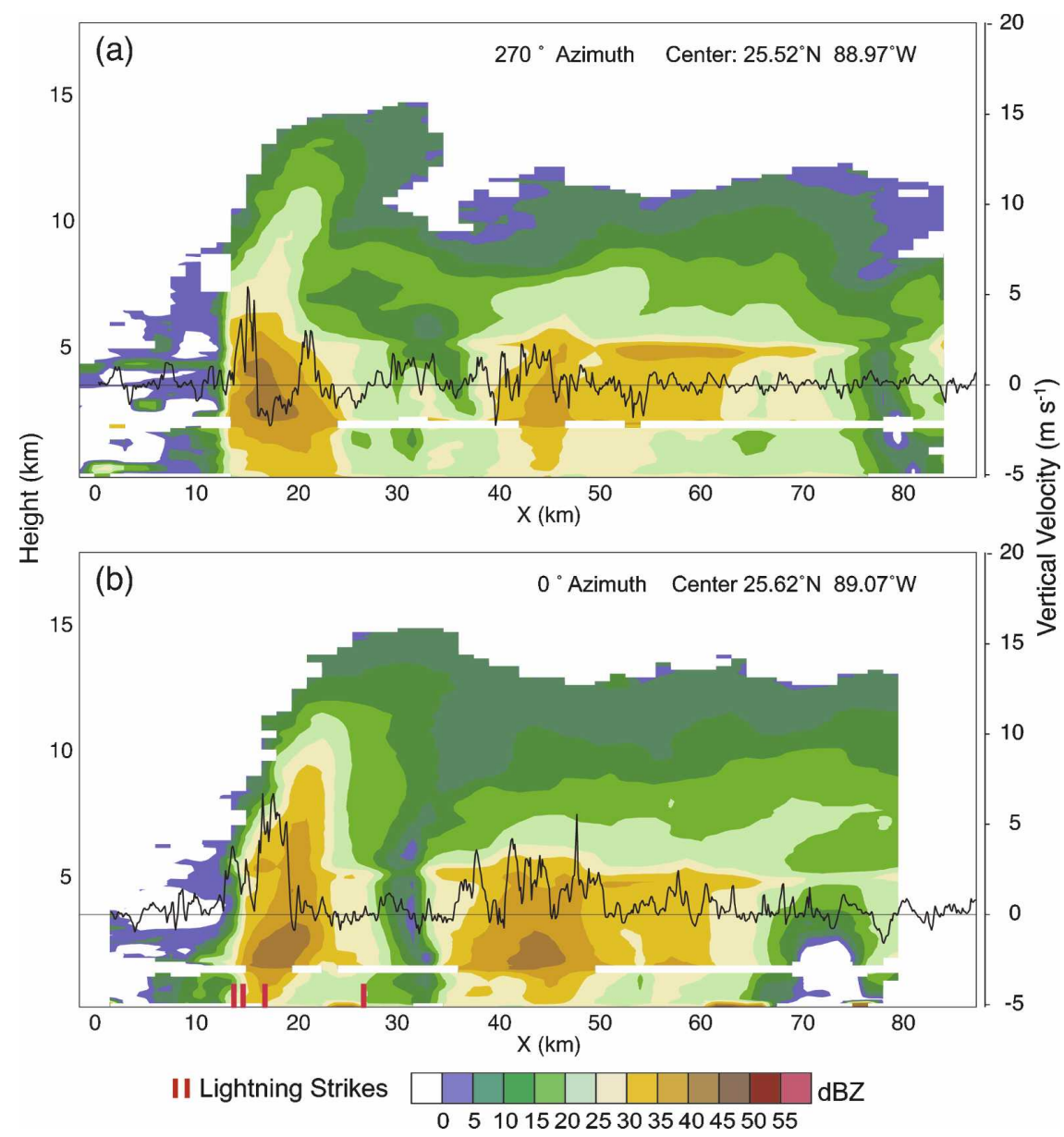

FIG. 9. Same as in Fig. 5, but with aircraft altitudes ranging from 1600 to $2200 \mathrm{~m}$ : (a) $270^{\circ}$ azimuth, 1720-1735 UTC 22 Sep and (b) $0^{\circ}$ azimuth, 1807-1818 UTC 22 Sep.

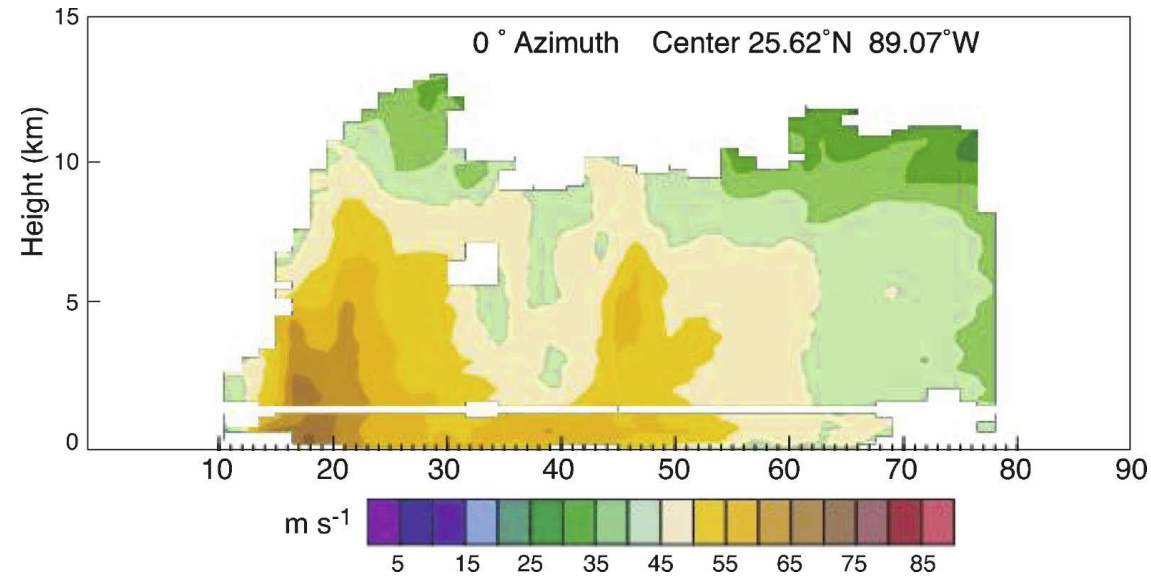

FIG. 10. A vertical cross section of the tangential wind through the northwest eyewall at $\sim 0^{\circ}$. The image is a composite made with data from the aircraft tail radar for the period 1807-1818 UTC 22 Sep. 


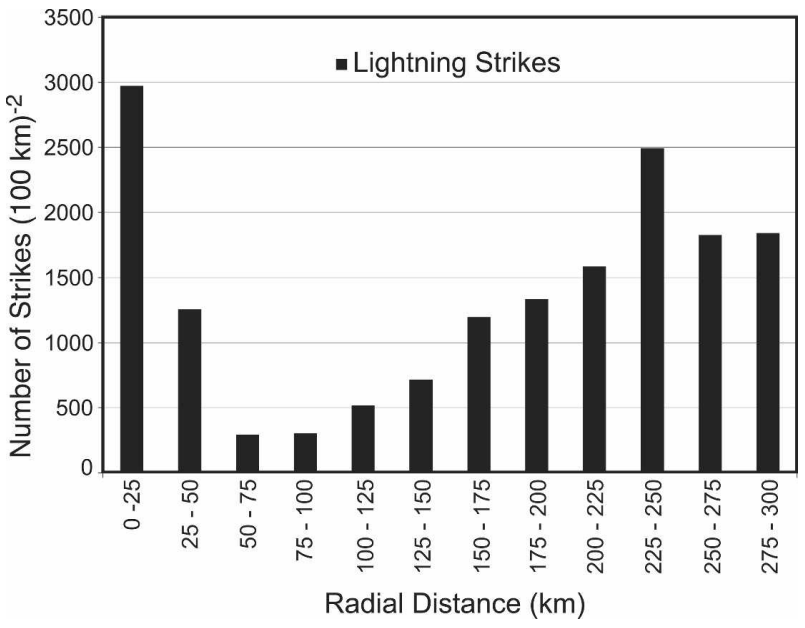

FIG. 11. Same as in Fig. 2, but for Hurricane Katrina between 0000 UTC 27 Aug and 0900 UTC 29 Aug.

Given that the diameter of the inner eyewall at this time was $\sim 45 \mathrm{~km}$, ice particles advected upward to a height of $8-10 \mathrm{~km}$ would be displaced $180^{\circ}$ cyclonically around the eyewall from a stationary convective source in only $\sim 24 \mathrm{~min}$. Through the next $6 \mathrm{~h}$, the inner eyewall completely decayed and the outer eyewall contracted to form a new primary eyewall.

\section{b. Katrina}

Lightning data for Hurricane Katrina include the period 0000 UTC 27 August-0900 UTC 29 August. Data collected prior to 0000 UTC 27 August were not included in this study, because of detection errors associated with the geometry of the LLDN over Florida (MMI). Hurricane Katrina, like Rita, contained an unusually large amount of eyewall lightning (Fig. 11). The maximum in storm-total strike density was detected in the $0-25-\mathrm{km}$ radial bin, containing 2973 strikes (100 $\mathrm{km})^{-2}$ during the $57-\mathrm{h}$ period. The eyewall region $(0-50$ $\mathrm{km}$ ) of Hurricane Katrina produced a total of 1684 strikes $(100 \mathrm{~km})^{-2}$ over the same period, which equates to a strike density of 709 strikes $(100 \mathrm{~km})^{-2}$ day $^{-1}$. Similar to Rita, a minimum in strike density occurred within the inner rainband region, with a secondary maximum in the outer rainband region (Fig. 11).

Hurricane Katrina produced several eyewall lightning outbreaks that showed similarities with those in observed Hurricane Rita. Like Rita, Hurricane Katrina produced an eyewall lightning outbreak in the middle of a period of RI, with eyewall flash density reaching a sharp maximum at 0300 UTC 27 August (Fig. 12). Similar to Rita, Katrina's eyewall contained intermittent lightning outbreaks during an ER cycle, with variable lightning densities observed from 1700 UTC 27 August to 0000 UTC 28 August. Finally, Katrina also produced an eyewall lightning outbreak during the time when MI was reached, between 1300 and 2200 UTC 28 August.

The remainder of this section will document the wellsampled MI eyewall outbreak. Detailed analyses of Katrina's RI and ER lightning outbreaks can be found

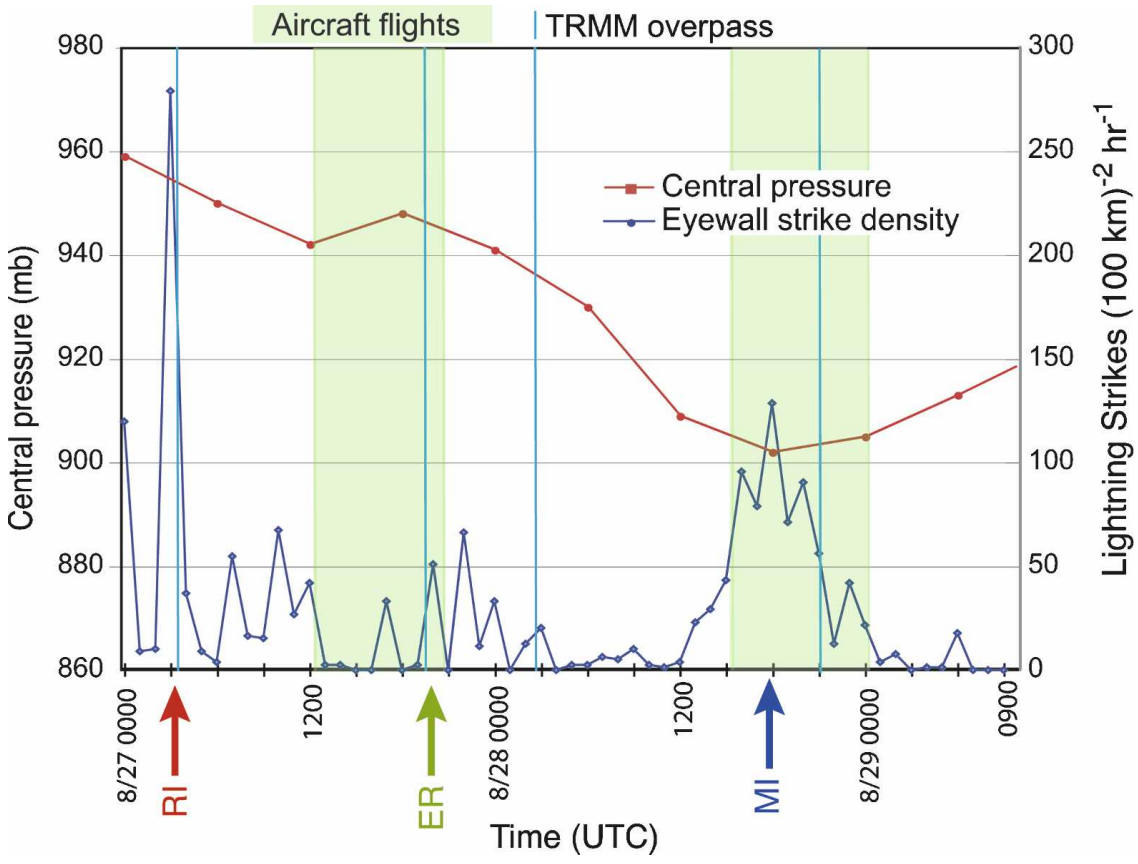

FIG. 12. Same as in Fig. 3, but for Hurricane Katrina. 

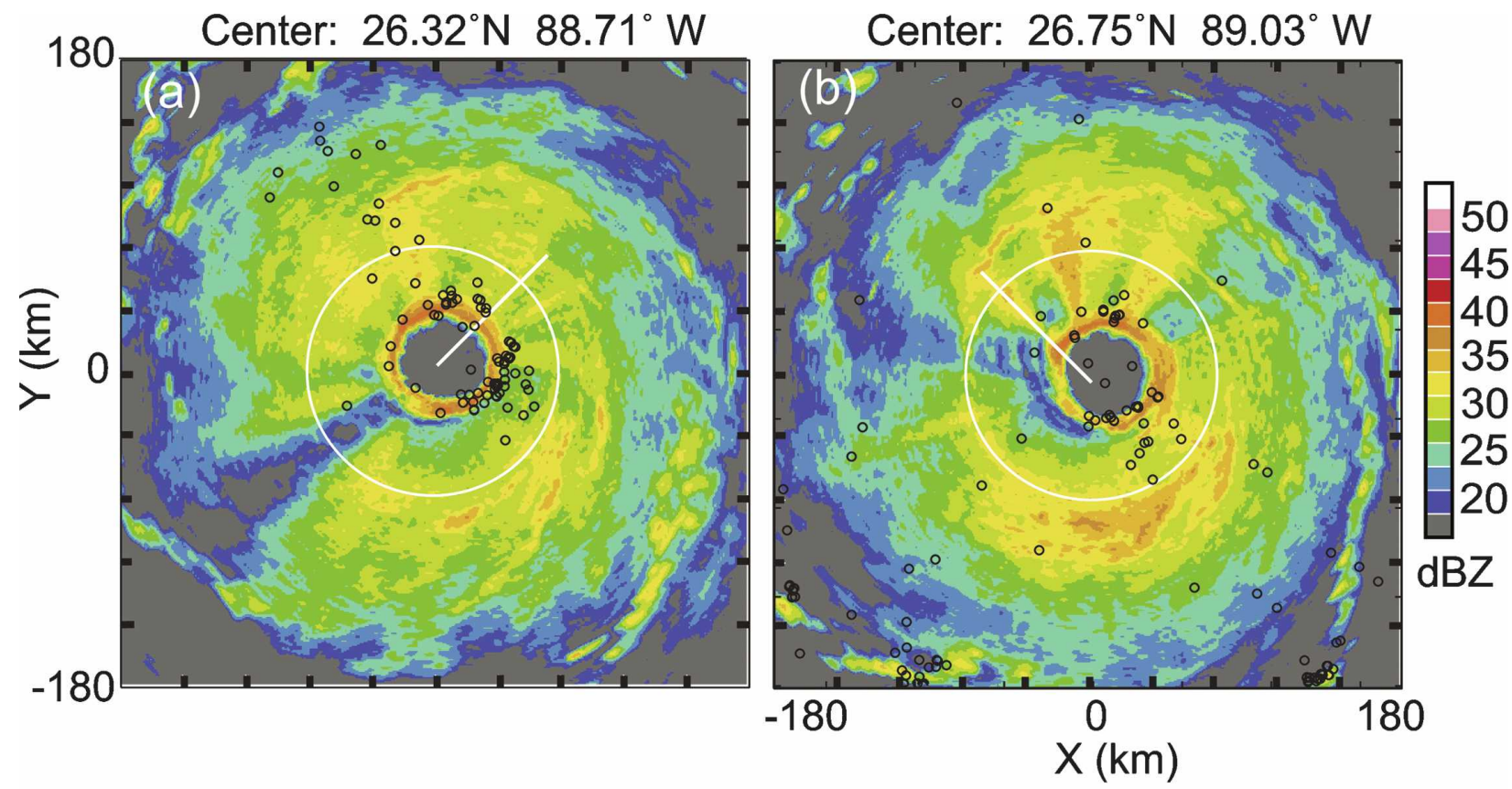

○ Lightning Strike

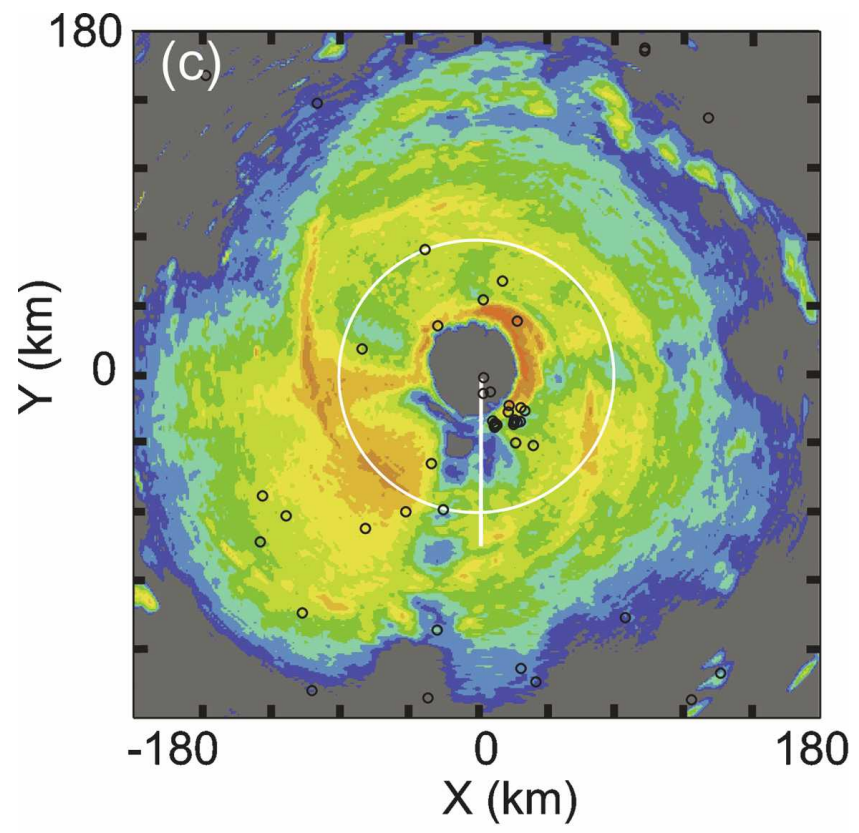

FIG. 13. Same as in Fig. 4, but for Hurricane Katrina on 28 Aug while the aircraft was near the storm center at an altitude of $\sim 2300 \mathrm{~m}$. The white radial lines indicate approximate locations of cross sections in Figs. 15a,c,d: (a) 1752, (b) 2036, and (c) 2324 UTC.

Center: $27.06^{\circ} \mathrm{N} 89.13^{\circ} \mathrm{W}$

in Squires (2006). Hurricane Katrina attained maximum intensity at 1800 UTC 28 September, with estimated minimum central pressure of $902 \mathrm{mb}$ and maximum sustained surface winds of $77 \mathrm{~m} \mathrm{~s}^{-1}$ (Knabb et al. 2005). The MI eyewall outbreak started at 1300 UTC 28 August and continued for approximately $9 \mathrm{~h}$, reaching a maximum strike density of 128 strikes $(100 \mathrm{~km})^{-2} \mathrm{~h}^{-1}$ at 1800 UTC (Fig. 12). This outbreak was quite sym- metric, with strikes detected in every azimuth of the eyewall (Fig. 13).

Figure 13a shows a relatively symmetric reflectivity pattern in the eyewall, with slightly higher reflectivities observed in southeastern and northern region of the eyewall at 1752 UTC 28 August. These regions also contained higher strike densities. The asymmetry in the pattern of active convection and strike density re- 
mained relatively stationary with respect to the storm center for the remainder of this outbreak, with the overall strike density maximum remaining in the southeastern region of the eyewall as the outbreak came to an end (Figs. 13b,c).

Vertical reflectivity profiles show that northeast and southwest regions of the eyewall contained maximum reflectivities below the freezing level $(\sim 5 \mathrm{~km})$, with 25 $\mathrm{dB} Z$ observed into the mixed phase region (Figs. $14 a, b)$. These two azimuths both contain relatively little lightning during the time of the pass, with lightning detected cyclonically downwind of each. The airplane pass through the northwest region of the eyewall recorded reflectivities that decrease rapidly with height above the melting level, which is characteristic of weak convection (Fig. 14c). This radial pass also contains the least amount of lightning when compared to the other passes through the eyewall. Downwind of the northwest eyewall pass, the western and southwestern regions of the eyewall contain the least lightning during the outbreak.

The deepest convection measured within the eyewall during this outbreak period was in the $180^{\circ}$ azimuth (Fig. 14d). This radial pass was flown approximately $5 \mathrm{~h}$ after maximum intensity was reached, at the time when Katrina had begun to weaken. Reflectivities of $30 \mathrm{~dB} Z$ were measured above $8 \mathrm{~km}$, with $20 \mathrm{~dB} Z$ extending to $\sim 11 \mathrm{~km}$. The flight level updraft for this part of the eyewall contained positive vertical velocities continuously for $15 \mathrm{~km}$ along the flight path. The peak values of PIC for the $180^{\circ}$ cross section was $\sim 0.6 \mathrm{~g} \mathrm{~m}^{-3}$ (Fig. $14 \mathrm{~d}$ ), and this azimuth also contains the greatest strike density.

On short time and spatial scales there can be uncertainties in the relationship between lightning strike density and PIC/brightness temperatures. For example, it is not clear from the lightning strike locations in Figs. 15a,b how well they coincide with lowest brightness temperatures and highest PIC values. This image contains lightning from 2102 to 2142 UTC, during which time there was a brief reduction in eyewall strike density just before a last local maximum was reached at 2300 UTC (Fig. 12). However, these two images do correlate well with the spatial distribution of strike density that was present for most of the 9-h outbreak (Figs. 13 and 15 ). The lowest $85-\mathrm{GHz}$ brightness temperatures were located in the southeastern and northern regions of the eyewall, with the western eyewall region void of temperatures $<225 \mathrm{~K}$ (Fig. 15a). The PIC values are also highest in the southeastern and northern regions of the eyewall, with both of these eyewall regions containing TRMM pixel values $>0.73 \mathrm{~g} \mathrm{~m}^{-3}$, while the western region contained very little lightning during the 9 -h pe- riod, values $<0.4 \mathrm{~g} \mathrm{~m}^{-3}$ (Fig. 15b). The IR satellite image in Fig. $15 \mathrm{c}$ is centered nearer to a peak in lightning activity during the MI outbreak, and provides a better overview of the distribution of the lightning relative to the location of the eye during the overall period represented in Fig. 15.

\section{Discussion}

The use of the LLDN lightning data in this study allowed continuous monitoring of Hurricanes Rita and Katrina, and did not require the implementation of a coastal proximity restriction used in Molinari et al. (1994, 1999). Because of the falloff in the lightning detection efficiency intrinsic to the NLDN data, MMI was forced to limit the analysis of lightning data in tropical cyclones to times when their centers were within 400 $\mathrm{km}$ of at least two direction-finding sensors.

Contrary to the results presented in MMI, eyewall lightning represented a dominant contribution to the lightning distribution in Hurricanes Rita and Katrina. Eyewall cloud-to-ground strikes were present more often then not during both hurricanes. When Molinari's coastal restriction is applied to the data for Rita and Katrina, the percent of hourly eyewall lightning observations decreases dramatically for Rita, while it remains nearly unchanged for Katrina (Table 1).

The length of lightning outbreaks also changed significantly with the implementation of Molinari's nearcoast limit (Table 1). The longest continuous eyewall lightning episode (defined as at least one detected lightning strike in each hourly period) in the four strongest hurricanes documented by MMI was $5 \mathrm{~h}$ in duration. In contrast, the longest eyewall lightning episodes for Hurricanes Rita and Katrina lasted for 31 and 22 h, respectively. Implementing a coastal restriction reduces these durations down to $12 \mathrm{~h}$ for Katrina, and only $4 \mathrm{~h}$ for Rita. These differences underscore the value of the LLDN data stream for remotely observing lightning in tropical storms.

\section{a. Implications of lightning morphology}

Hurricanes Rita and Katrina both contained nearly symmetric eyewall lightning outbreaks during the period when maximum intensity was reached. The eye diameter for both Hurricanes Rita and Katrina had reached a minimum during the time of maximum intensity, and radar and TRMM data showed evidence of symmetric, enhanced convection. Aircraft flight-level data show that vertical motion associated with the convection was also enhanced, thus promoting elevated rates of charge separation within the eyewall. The re- 

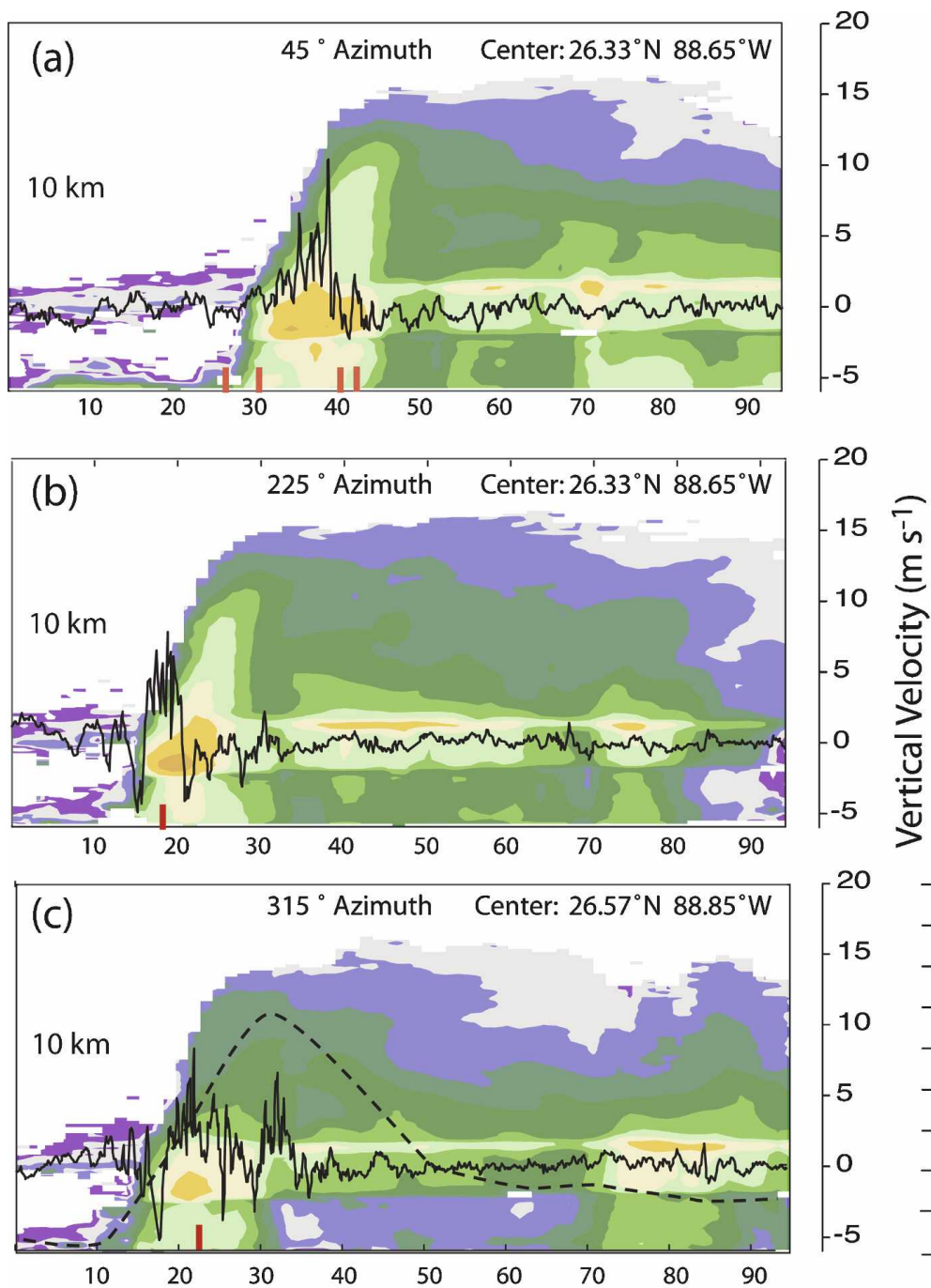

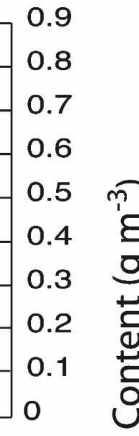

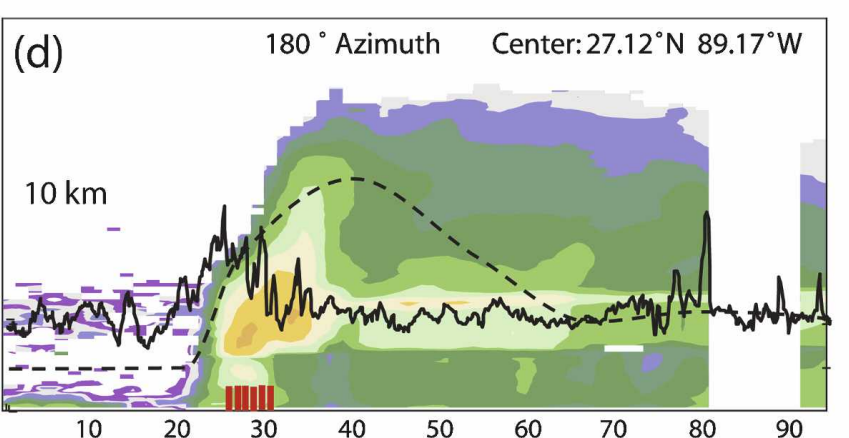

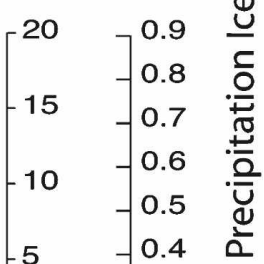

II Lightning Strikes

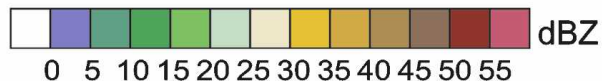

FIG. 14. Same as in Fig. 5, but for Hurricane Katrina on 28 Aug. Radial passes were made at aircraft altitudes ranging from 2400 to $2600 \mathrm{~m}$ : (a) $45^{\circ}$ azimuth, $1725-1755 \mathrm{UTC}$; (b) $225^{\circ}$ azimuth, 1755-1818 UTC; (c) 315 azimuth, 1923-1946 UTC; and (d) $180^{\circ}$ azimuth, 2231-2253 UTC. Radial distribution of level 12 PIC (dashed line) obtained from the 2122 UTC 28 Aug TRMM image overlaid on (c) and (d). 

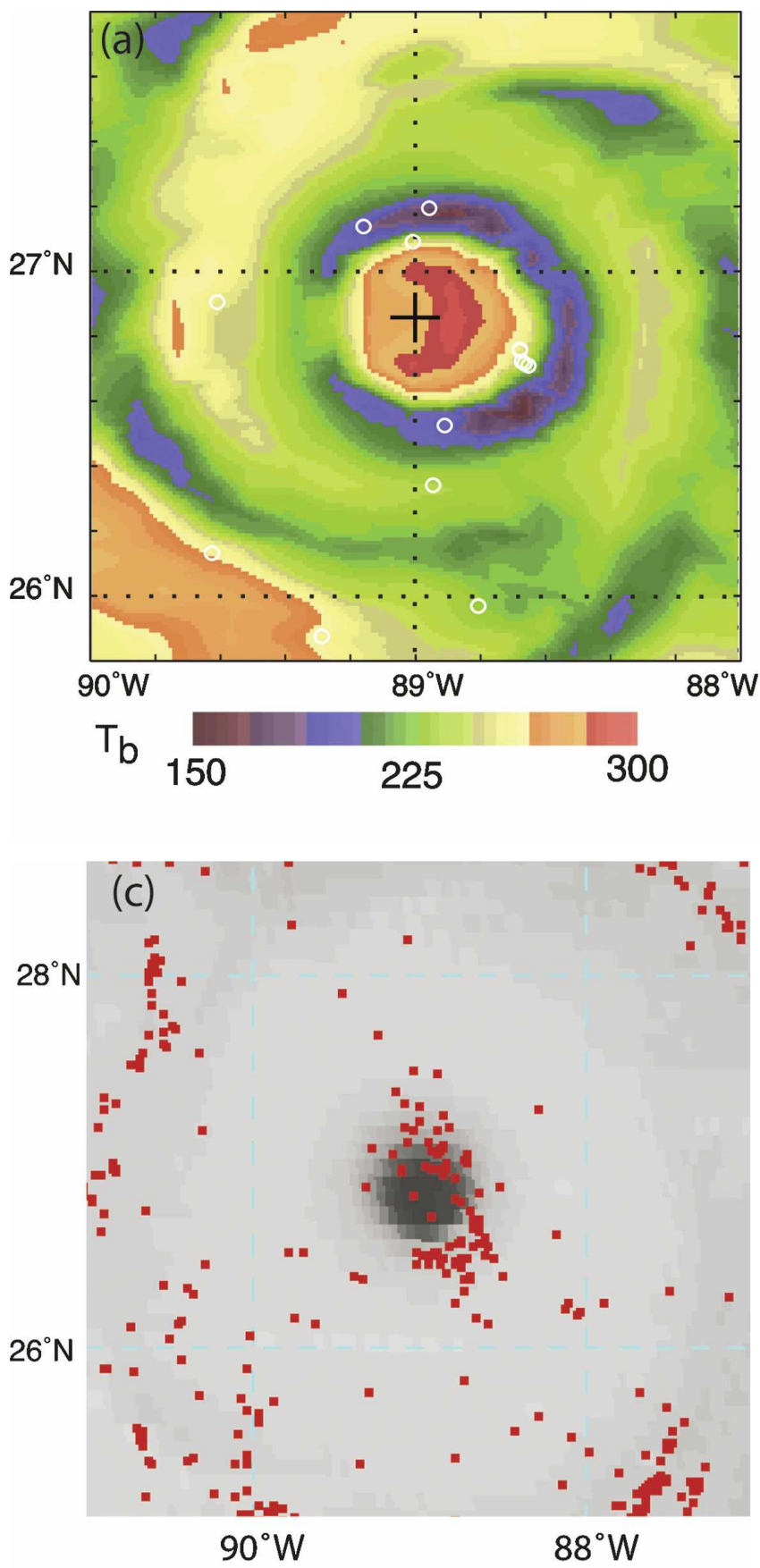

Lightning Strike

sulting strong symmetric electric field would be less prone to dissipation by wind shear and mixing prevalent in mature hurricanes (Black and Hallett 1999). The eyewall of Hurricane Katrina also displayed eyewall structure that was at its most vertical during the time minimum eye diameter was reached. The more vertical slope of the eyewall updraft would act to decrease the outward horizontal dilution of charged particles, result-

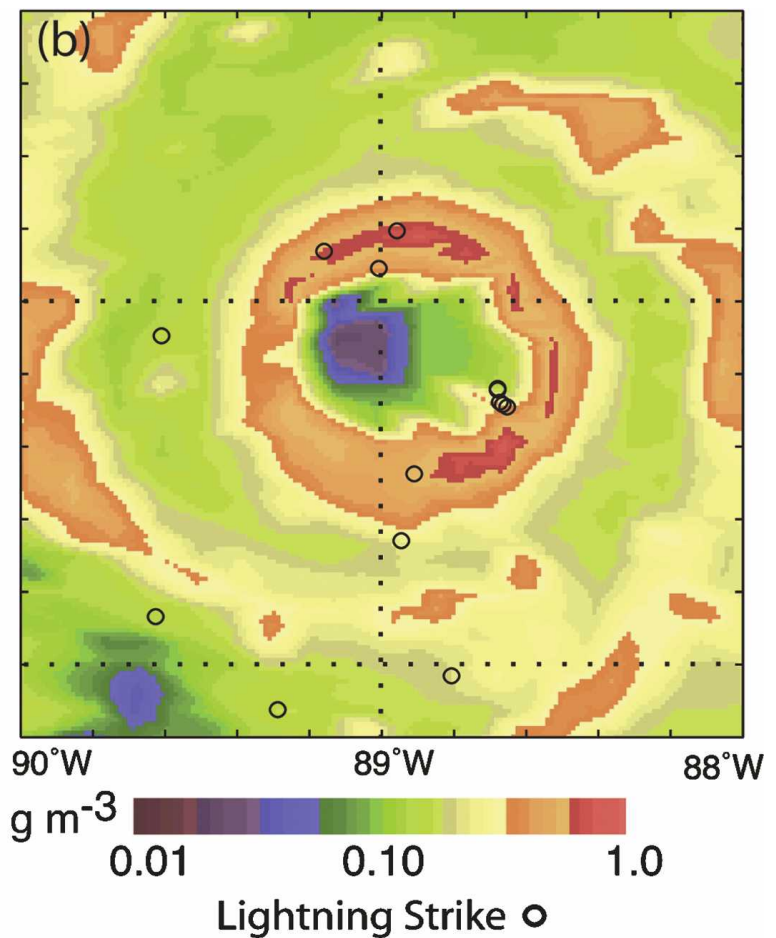

FIG. 15. (a), (b) Same as in Fig. 6, but for Hurricane Katrina at 2122 UTC 28 Aug. Each TRMM image is overlaid with lightning strike locations from 2102 to 2142 UTC: (a) $85-\mathrm{GHz}$ TMI image with lightning (white circles), (b) layer 12 (8-10 $\mathrm{km}$ ) precipitation ice content image with lightning (black circles), (c) GOES-12 infrared satellite image taken of Hurricane Katrina at 2045 UTC 28 Aug; overlaid onto the image are lightning strike locations (red dots) from 2000 to 2100 UTC. ing in greater charge densities within the eyewall and a stronger cloud-to-ground electric dipole (Black and Hallett 1999). The symmetric character of the charge separation process and more vertical orientation of the convection allows the eyewall to sustain strong electric fields for extended periods of time and to produce the observed enhanced strike densities (Fig. 16a).

In contrast, lower-than-expected strike densities can 
TABLE 1. Comparison of the results reported by Molinari et al. (1994, 1999) and the results of this study. Eyewall flashes from Molinari et al. (1994) are for Hurricane Andrew (1991), the most intense storm they sampled, and the eyewall region used in that study was $0-40 \mathrm{~km}$ from the storm center. The percent of eyewall lightning is the percent of the total hourly observations that contained at least one eyewall flash. The longest duration of continuous eyewall lightning is the number of consecutive hours during which at least one eyewall strike was detected. The result in MMI for the percentage of eyewall lightning is an average taken from the total number of hourly observations for the four strongest storms examined. The longest duration of eyewall lightning is the maximum value recorded for the four strongest storms examined, and the eyewall region used was 0-60 km. For Hurricanes Rita and Katrina the eyewall region was defined as $0-50 \mathrm{~km}$. The columns labeled Rita and Katrina show results that include all the lightning data, whereas the last two columns show results that only include lightning data while these storms were within $400 \mathrm{~km}$ from the coast.

\begin{tabular}{lccccc}
\hline \hline & Molinari & Rita & Katrina & Rita $(400 \mathrm{~km})$ & Katrina $(400 \mathrm{~km})$ \\
\hline Eyewall flashes $\left(10^{-4} \mathrm{~km}^{-2} \mathrm{day}^{-1}\right)$ & 54 (Andrew 1991) & 986 & 709 & 145 & 849 \\
Percentage of eyewall lightning & $7 \%$ & $70 \%$ & $82 \%$ & $45 \%$ & $81 \%$ \\
Longest duration of continuous eyewall lightning & $5 \mathrm{~h}$ & $31 \mathrm{~h}$ & $22 \mathrm{~h}$ & $4 \mathrm{~h}$ & $12 \mathrm{~h}$ \\
\hline
\end{tabular}

accompany deep eyewall convection, if that convection is asymmetric about the eyewall, as observed in mature Hurricane Rita (i.e., Figs. 8 and 9). The large vertical shear of the horizontal winds within the eyewall of mature hurricanes can cause locally enhanced charge separation created by intense asymmetric convection to be advected away or mixed out. This differential horizontal advection would cause a rapid reduction in electric field strength and diminish cloud-to-ground strike density (Fig. 16b).

The duration of the eyewall lightning outbreaks can also be affected by the amount of precipitation-sized ice created within the eyewall. The RI eyewall lightning outbreaks that occurred during each storm had very similar strike density evolutions. The strike density increased (decreased) rapidly before (after) reaching the maximum strike density for the respective eyewall lightning outbreak. It is suggested that while the large amounts of charge separation occurred, enhanced amounts of precipitation-sized ice and cloud ice were being produced and supported by unusually robust updrafts within the eyewall during the beginning half of the lightning outbreak. These enhanced amounts of ice, either in terms of greater concentrations or larger particles, were then distributed and recycled throughout the eyewall, which would cause the nucleation and evaporation of much of the supercooled water present within the eyewall cloud. The reduction in supercooled water concentration would lead to a sharp reduction in the rate of charge separation and a resultant rapid decrease in strike density within the eyewall.

For each hurricane, the MI eyewall lightning outbreaks had a lower strike density than that of the RI lightning outbreaks, however the MI outbreaks were longer lived $(>8 \mathrm{~h})$. If, as the observations suggest, the updrafts and resultant charge separation within the eyewall are weaker during MI outbreaks than during the RI outbreaks, MI outbreaks should result in less charge separation and lower eyewall strike density. However, during maximum intensity it is suggested that enhanced updrafts are sustained for longer periods of time, thus supporting an enhanced charge separation process and enhanced strike density within the eyewall for an extended period of time.

Possible explanations for enhanced convection have been proposed by other studies. Black et al. (1994) have shown that appreciable slantwise convective available potential energy (SCAPE) within the eyewall of a mature hurricane can result in updrafts of $>20 \mathrm{~m} \mathrm{~s}^{-1}$ and enhanced convection that is symmetric about the eye. If total upward mass flux within the eyewall remained constant throughout the contraction period of the eye, the upward mass flux per unit area and vertical velocities would have to increase. A recent study has also suggested the possibility that high- $\theta_{\mathrm{e}}$ air contained within the eye can mix into the eyewall and cause buoyantly driven updrafts (Persing and Montgomery 2003).

\section{b. Applications of LLDN lightning data to hurricanes}

The possibility of using ground-based lightning detection to forecast intensity and structure change in hurricanes has been proposed in previous studies (Molinari et al. 1994, 1999; Samsury and Orville 1994). The results of this paper provide additional evidence that changes in eyewall lightning morphology reflect changes in convective structure within the eyewall, and this evolution can be continuously monitored with the LLDN. For example, it is possible to infer that an eyewall contraction took place as Hurricane Rita underwent rapid intensification by examining the time series of the radial distribution of lightning strike density. A graphic product that displays changes in strike counts in radially distributed bins can be easily constructed as an aid to forecasters.

Although, the mechanisms for charge separation are broadly understood, representing the details of cloud dynamics and microphysics associated with eyewall 


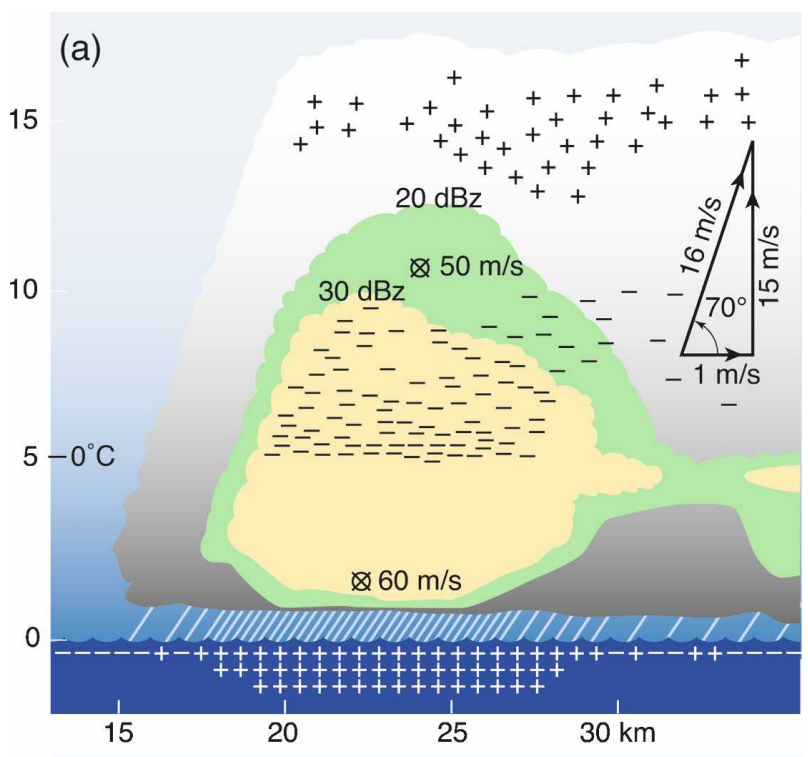

(b)

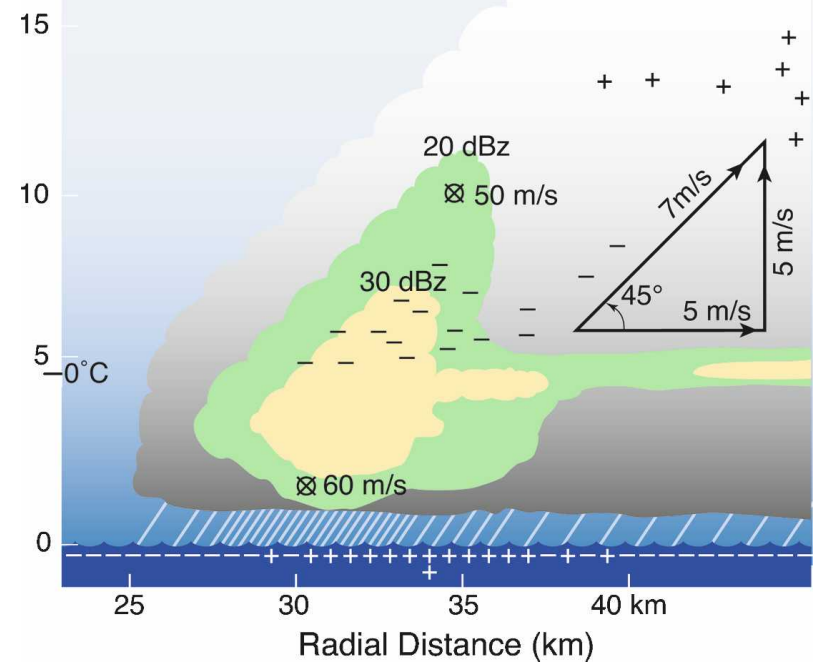

FIG. 16. Conceptual schematic showing radar reflectivity (30 $\mathrm{dB} Z$ yellow and $20 \mathrm{dBZ}$ green), charge distribution [positive $(+)$ and negative ( - ) charges], freezing level, and wind vectors. Vertical cross sections of (a) an eyewall that produces a significant number of lightning strikes and (b) one that produces few or no lightning strikes.

lightning outbreaks in numerical models is an emerging field (e.g., Helsdon et al. 2001; Fierro et al. 2007). The LLDN provides a rich data source of lightning for numerical modelers to validate their results.

The most vigorous eyewall lightning outbreaks in both storms analyzed here occurred after the intensification period began (RI outbreaks), and thus provided no warning that the storm would intensify. However, RI outbreaks may signal that the storm will continue to deepen. The MI outbreaks began approximately $4-5 \mathrm{~h}$ before maximum intensity was reached, a phenomenon also documented in MMI. Thus, the occurrence of MI outbreaks may provide forecasters with additional evidence, which can be used in the context of all other available information, to help determine if a storm has passed maximum intensity and is beginning to fill. However, more research is needed to establish when and if the patterns seen in the storms studied here can be generalized to other tropical cyclones.

Recently investigators have capitalized on the correlation between convective rainfall and lightning rates to improve numerical forecasts of storms through various approaches to assimilating lightning data (Alexander et al. 1999; Chang et al. 2001; Papadopoulos et al. 2005; Pessi et al. 2005). Similar correlations have been found between lightning rates and precipitable ice, which may be less sensitive to the character of the air mass (Williams et al. 1992; Toracinta et al. 2002). Therefore, the opportunity exists to assimilate LLDN data over datasparse regions to influence the distribution of convection at the core of modeled tropical storms.

\section{Summary and conclusions}

Data collected by the Long-Range Lightning Detection Network (LLDN), TRMM satellite, and reconnaissance aircraft have been used to investigate the morphology of lightning outbreaks in the eyewalls of Hurricanes Rita (2005) and Katrina (2005). The LLDN is one of few observing systems, outside of geostationary satellites, which provide continuous real-time data throughout a synoptic-scale coverage area over the open ocean.

The morphology of the lightning outbreaks in Rita and Katrina showed many similarities. However, the nature of lightning outbreaks in other tropical storms may vary, depending on the storm's environment and strength. Therefore, any conclusions based on the specific observations of eyewall outbreaks documented in this paper must be seen as tentative until additional investigations can provide a more complete view of the variety of lightning signatures in tropical cyclones. $\mathrm{Nev}$ ertheless, the correspondence of the lightning outbreaks with observed cores of enhanced reflectivity and high precipitable ice concentrations, shows that the LLDN data stream holds promise for future quantitative applications to diagnose and predict hurricane convective structure and evolution.

Both Hurricanes Rita and Katrina produced their greatest hourly eyewall strike density during their respective periods of rapid intensification. However, the morphology of these two RI outbreaks and their associated convective structures proved to be different. 
Hurricane Rita's eyewall outbreak lasted $\sim 3 \mathrm{~h}$, and was quasisymmetric about the eye, with cloud-to-ground lightning strikes detected in every azimuthal section of the eyewall. In contrast, Hurricane Katrina's outbreak lasted $\sim 20 \mathrm{~min}$, with the large majority of the eyewall strikes detected in the southeastern region of the eyewall (Squires 2006).

One of the most intriguing results of the LLDN lightning analysis is that Hurricanes Rita and Katrina both produced long-lived eyewall outbreaks centered around the time when maximum intensity was reached. The MI eyewall strike densities were comparable, with hourly strike densities between 140 and 175 strikes $(100 \mathrm{~km})^{-2}$ for each storm. Hurricane Katrina's MI eyewall outbreak reached a maximum within the same hour as minimum central pressure was reached as estimated by the NHC. While the eyewall of Hurricane Katrina was completely enclosed and circular, eyewall strike density values were not quite symmetric about the eye, showing higher values in the northern and southeast regions of the eyewall.

During eyewall replacement cycles, the eyewall region produced brief periods of cloud-to-ground lightning in both storms. Hurricane Rita produced one ER outbreak that lasted less than $2 \mathrm{~h}$, whereas Katrina produced multiple subhourly ER eyewall outbreaks. The hourly strike density of ER outbreaks in both storms was $\sim 50$ strikes $(100 \mathrm{~km})^{-2} \mathrm{~h}^{-1}$. Aircraft radar data showed that the ER lightning outbreaks in both storms were produced by the decaying inner eyewall, and not by the developing outer eyewall.

Aircraft radar reflectivity data showed the best spatial correlation with lightning strikes. When areas of high strike density within the eyewall were detected they were consistently collocated with areas of high reflectivity. The strength and vertical development of convection were also correlated with high strike density. In particular, areas of eyewall convection that exhibited 30-dB $Z$ reflectivities at higher altitudes (i.e., $>7$ $\mathrm{km})$, along with reflectivity values that decreased slowly with height above the freezing level contained greater lightning strike densities.

The TRMM 85-GHz and PIC products both displayed spatial and temporal correspondence with the eyewall lightning. Low $85-\mathrm{GHz}$ brightness temperatures and high PIC were not always indicative of the presence of eyewall lightning; however, when significant amounts of eyewall lightning were detected, low brightness temperatures and high PIC were always recorded within close proximity of the strikes. Moreover, the differences in location were consistent with advective processes.

Consistent with the great intensity of these two hur- ricanes, the $85-\mathrm{GHz}$ brightness temperatures within their eyewalls $(<150 \mathrm{~K})$ were historically low when compared to the previous investigations. Cecil et al. (2002a) conducted a frequency study of 261 TRMM overpasses of mature hurricanes and found that less than $15 \%$ of mature hurricane eyewalls contain $85-\mathrm{GHz}$ brightness temperatures less than $150 \mathrm{~K}$.

Maximum vertical velocities observed in flight-level data in the eyewalls of Rita and Katrina varied from 3 to $16.5 \mathrm{~m} \mathrm{~s}^{-1}$. The single highest vertical velocity (16.5 $\mathrm{m} \mathrm{s}^{-1}$ ) was measured during the time of the highest eyewall strike density; however, a more general correlation was not found. It is suggested that the lack of a consistent correlation is the result of limited sampling in rapidly evolving convection and the healthy tendency for reconnaissance pilots to avoid convective cores.

In summary, the results of an in-depth analysis of lightning outbreaks in the eyewall of two category 5 hurricanes described in this paper show promise for the use of continuous LLDN data to remotely infer the temporal evolution of hurricane convective core structure. It is the hope of the authors that this paper will spur interest in the application of LLDN data to the challenges presented by tropical cyclones.

Acknowledgments. We thank Drs. Ken Cummins and Nick Demetriades of the Vaisala Thunderstorm Unit who helped motive this study, provided processed data, and editorial suggestions. Thanks go to Drs. Gary Barnes and Tom Schroeder for their constructive input. We are grateful to Ed Zipser, Dan Cecil, and one anonymous reviewer for their thorough reviews that resulted in a better final manuscript. We would also like to thank the NOAA/AOML/Hurricane Research Division and NOAA/NWS/National Hurricane Center for their efforts in the collection of and processing of the data used in this study. We would especially like to thank John Gamache and Neal Dorst of the HRD for their assistance in making the aircraft radar and 1-s data available to us. We are grateful to Antti Pessi for his technical assistance with the satellite image processing and to Nancy Hulbirt for her graphics expertise. TRMM satellite data have been provided by the TRMM Science Data and Information System at the Goddard Space Flight Center, Greenbelt, Maryland. This work is supported by the Office of Naval Research under Grant N000140510551.

\section{REFERENCES}

Alexander, G. D., J. A. Weinman, V. M. Karyampudi, W. S. Olson, and A. C. L. Lee, 1999: The effect of assimilating rain rates derived from satellites and lightning on forecasts of the 1993 superstorm. Mon. Wea. Rev., 127, 1433-1457. 
Beard, K. V. K., and H. T. Ochs, 1986: Charging mechanisms in clouds and thunderstorms. The Earth's Electrical Environment, E. P. Krider and R. G. Robble, Eds., National Academy Press, 114-130.

Black, R. A., 1990: Radar reflectivity-ice water content relationships for use above the melting level in hurricanes. J. Appl. Meteor., 29, 955-961.

- and J. Hallett, 1986: Observations of the distribution of ice in hurricanes. J. Atmos. Sci., 43, 802-822.

- and 1999: Electrification of the hurricane. J. Atmos. Sci., 56, 2004-2028.

_, H. B. Bluestein, M. L. Black, and J. Hallett, 1994: Unusually strong vertical motions in a Caribbean hurricane. Mon. Wea. Rev., 122, 2722-2739.

Bogner, P. B., G. M. Barnes, and J. L. Franklin, 2000: Conditional instability and shear for six hurricanes over the Atlantic Ocean. Wea. Forecasting, 15, 192-207.

Cecil, D. J., and E. J. Zipser, 1999: Relationships between tropical cyclone intensity and satellite-based indicators of inner core convection: $85-\mathrm{GHz}$ ice-scattering signature and lightning. Mon. Wea. Rev., 127, 103-123.

and S. W. Nesbitt, 2002a: Reflectivity, ice scattering, and lightning characteristics of hurricane eyewalls and rainbands. Part I: Quantitative description. Mon. Wea. Rev., 130, 771-784.

,-- , and,$- 2002 \mathrm{~b}$ : Reflectivity, ice scattering, and lightning characteristics of hurricane eyewalls and rainbands. Part II: Intercomparison of observations. Mon. Wea. Rev., 130, 785-801.

— S. J. Goodman, D. J. Boccippio, E. J. Zipser, and S. W. Nesbitt, 2005: Three years of TRMM precipitation features. Part I: Radar, radiometric, and lightning characteristics. Mon. Wea. Rev., 133, 543-566.

Chang, D.-E., J. A. Weinman, C. A. Morales, and W. S. Olson, 2001: The effect of spaceborne microwave and ground-based continuous lightning measurements on forecasts of the 1998 Groundhog Day Storm. Mon. Wea. Rev., 129, 1809-1833.

Corbosiero, K. L., 2003: The relationship between storm motion, vertical wind shear, and convective asymmetries in tropical cyclones. J. Atmos. Sci., 60, 366-376.

— and J. Molinari, 2002: The effect of vertical wind shear on the distribution of convection in tropical cyclones. Mon. Wea. Rev., 130, 2110-2132.

Cramer, J. A., and K. L. Cummins, 1999: Long-range and transoceanic lightning detection. Proc. 11th Int. Conf. on Atmospheric Electricity, Guntersville, AL, Amer. Meteor. Soc., 250-253.

Cummins, K. L., M. J. Murphy, E. A. Bardo, W. L. Hiscoz, R. D. Pyle, and A. E. Pifer, 1998: A combined TOA/MDF technology upgrade of the U.S. National Lightning Detection Network. J. Geophys. Res., 103, 9035-9044.

R. B. Pyle, and G. Fournier, 1999: An integrated North American lightning detection network. Preprints, 11th Int. Conf. on Atmospheric Electricity, Guntersville, AL, Amer. Meteor. Soc., 218-221.

Demetriades, N. W., and R. L. Holle, 2005: Long-range lightning applications for hurricane intensity. Preprints, First Conf. on Meteorological Applications of Lightning Data, San Diego, CA, Amer. Meteor. Soc., P2.8.

$\longrightarrow$, and —, 2006: Long range lightning nowcasting applications for tropical cyclones. Preprints, Second Conf. on Meteorological Applications of Lightning Data, Atlanta, GA, Amer. Meteor. Soc., P2.15.
Emanuel, K. A., 1986: An air-sea interaction theory for tropical cyclones. Part I: Steady-state maintenance. J. Atmos. Sci., 43, 585-605.

Fierro, A., L. Leslie, E. Mansell, J. Straka, D. MacGorman, and C. Ziegler, 2007: A high-resolution simulation of microphysics and electrification in an idealized hurricanelike vortex. $\mathrm{Me}$ teor. Atmos. Phys., 98, 13-33.

Fiorino, S. T., and E. A. Smith, 2006: Critical assessment of microphysical assumptions within TRMM radiometer rain profile algorithm using satellite, aircraft, and surface datasets from KWAJEX. J. Appl. Meteor. Climatol., 45, 754-786.

Gamache, J. F., R. A. Houze Jr., and F. D. Marks Jr., 1993: Dualaircraft investigation of the inner core of Hurricane Norbert. J. Atmos. Sci., 50, 3221-3243.

Gray, W. M., 1965: Calculations of cumulus vertical draft velocities in hurricanes from aircraft observations. J. Appl. Meteor., 4, 463-474.

Helsdon, J. H., W. A. Wojcik, and R. D. Farley, 2001: An examination of thunderstorm-charging mechanisms using a twodimensional storm electrification model. J. Geophys. Res., 106, 1165-1192.

Heymsfield, G. M., J. B. Halverson, J. Simpson, L. Tian, and T. P. Bui, 2001: ER-2 Doppler radar investigations of the eyewall of Hurricane Bonnie during the Convection and Moisture Experiment-3. J. Appl. Meteor., 40, 1310-1330.

Jorgensen, D. P., 1984: Meso-scale and convective scale characteristics of mature hurricanes. Part I: General observations by research aircraft. J. Atmos. Sci., 41, 1268-1285.

— , E. J. Zipser, and M. A. LeMone, 1985: Vertical motions in intense hurricanes. J. Atmos. Sci., 42, 839-856.

Knabb, R. D., J. R. Rhome, and D. P. Brown, 2005: Hurricane Katrina. National Hurricane Center, 43 pp. [Available online at http://www.nhc.noaa.gov/pdf/TCR-AL122005_ Katrina.pdf.]

_ D. P. Brown, and J. R. Rhome, 2006: Hurricane Rita. National Hurricane Center, 33 pp. [Available online at http:// www.nhc.noaa.gov/2005atlan.shtml.]

Kummerow, C., and Coauthors, 2001: The evolution of the Goddard profiling algorithm (GPROF) for rainfall estimation from passive microwave sensors. J. Appl. Meteor., 40, 18011820.

Lee, T. F., F. J. Turk, J. Hawkins, and K. Richardson, 2002: Interpretation of TRMM TMI images of tropical cyclones. Earth Interactions, 6. [Available online at http://EarthInteractions. org.]

Lyons, W. A., and C. S. Keen, 1994: Observations of lightning in convective supercells within tropical storms and hurricanes. Mon. Wea. Rev., 122, 1897-1916.

Marks, F. D., Jr., 1985: Evolution of the structure of precipitation in Hurricane Allen (1980). Mon. Wea. Rev., 113, 909-930.

Marshall, T. C., and W. D. Rust, 1991: Electric field soundings through thunderstorms. J. Geophys. Res., 96, 22 297-22 306.

$[, \ldots$, and M. Stolzenburg, 1995: Electrical structure and updraft speeds in thunderstorms over the southern Great Plains. J. Geophys. Res., 100, 1001-1016.

Mohr, K. I., J. S. Famiglietti, and E. J. Zipser, 1999: The contribution to tropical rainfall with respect to convective system type, size, and intensity estimated from the $85-\mathrm{GHz}$ icescattering signature. J. Appl. Meteor., 38, 596-606.

Molinari, J., P. K. Moore, V. P. Idone, R. W. Henderson, and A. B. Saljoughy, 1994: Cloud-to-ground lightning in Hurricane Andrew. J. Geophys. Res., 99, 16 665-16 676.

— P. Moore, and V. Idone, 1999: Convective structure of hur- 
ricanes as revealed by lightning locations. Mon. Wea. Rev., 127, $520-534$.

Nesbitt, S. W., E. J. Zipser, and D. J. Cecil, 2000: A census of precipitation features in the tropics using TRMM: Radar, ice scattering, and lightning observations. J. Climate, 13, 40874106.

Orville, R. E., and B. Vonnegut, 1974: Lightning detection from satellites. Electrical Processes in Atmospheres, H. Dolezalek and R. Reiter, Eds., Steinkopff Verlag, 750-753.

—, R. W. Henderson, and L. F. Bosart, 1983: An east coast lightning detection network. Bull. Amer. Meteor. Soc., 64, 1029-1037.

— , G. R. Huffines, W. R. Burrows, R. L. Holle, and K. L. Cummins, 2002: The North American Lightning Detection Network (NALDN)—First results: 1998-2000. Mon. Wea. Rev., 130, 2098-2109.

Papadopoulos, A., T. G. Chronis, and E. N. Anagnostou, 2005: Improving convective precipitation forecasting through assimilation of regional lightning measurements in a mesoscale model. Mon. Wea. Rev., 133, 1961-1977.

Persing, J., and M. T. Montgomery, 2003: Hurricane superintensity. J. Atmos. Sci., 60, 2349-2371.

Pessi, A. T., S. Businger, T. Cherubini, K. L. Cummins, and T. Turner, 2005: Toward the assimilation of lightning data over the Pacific Ocean into a mesoscale NWP model. Preprints, First Conf. on Meteorological Applications of Lightning Data, San Diego, CA, Amer. Meteor. Soc., 6.3.

Samsury, C. E., and R. E. Orville, 1994: Cloud-to-ground lightning in tropical cyclones: A study of hurricanes Hugo (1989) and Jerry (1989). Mon. Wea. Rev., 122, 1887-1896.

Saunders, C. P. R., 1995: Thunderstorm electrification. Handbook of Atmospheric Electrodynamics, Vol. 1, V. Volland, Ed., CRC Press, Inc., 61-92.

— W. D. Keith, and R. P. Mitzeva, 1991: The influence of liquid water on thunderstorm charging. J. Geophys. Res., 96, $11007-11017$.

Squires, K., 2006: Analysis of lightning outbreaks in the eyewalls of two category 5 hurricanes. M.S. thesis, Dept. of Meteorology, University of Hawaii at Manoa, 77 pp. [Available online at http://www.soest.hawaii.edu/MET/Faculty/businger/ hurrlight/MastersThesis.pdf.]

Szoke, E. J., E. J. Zipser, and D. P. Jorgensen, 1986: A radar study of convective cells in mesoscale systems in GATE. Part I: Vertical profile statistics and comparison with hurricanes. $J$. Atmos. Sci., 43, 182-197.

Takahashi, T., 1978: Riming electrification as a charge generation mechanisms in thunderstorms. J. Atmos. Sci., 35, 1536-1548.

Toracinta, E. R., D. J. Cecil, E. J. Zipser, and S. W. Nesbitt, 2002: Radar, passive microwave, and lightning characteristics of precipitating systems in the Tropics. Mon. Wea. Rev., 130, 802-824.

Williams, E. R., S. A. Rutledge, S. G. Goetis, N. Renno, E. Rassmussen, and T. Rickenbach, 1992: A radar and electrical study of tropical "hot towers." J. Atmos. Sci., 49, 1386-1395.

Yuter, S. E., and R. A. Houze Jr., 1995: Three-dimensional kinematic and microphysical evolution of Florida cumulonimbus. Part I: Spatial distribution of updrafts, downdrafts, and precipitation. Mon. Wea. Rev., 123, 1921-1940.

Zipser, E. J., 1994: Deep cumulonimbus cloud systems in the Tropics with and without lightning. Mon. Wea. Rev., 122, 1837-1851.

— events in GATE. Part II: Synthesis and model core structure. J. Atmos. Sci., 37, 2458-2469.

- , and K. R. Lutz, 1994: The vertical profile of radar reflectivity of convective cells: A strong indicator of storm intensity and lightning probability? Mon. Wea. Rev., 122, 1751-1759.

—, D. J. Cecil, C. Liu, S. W. Nesbitt, and D. P. Yorty, 2006: Where are the most intense thunderstorms on earth? Bull. Amer. Meteor. Soc., 87, 1057-1071.

Ziv, A., and Z. Levin, 1974: Thundercloud electrification: Cloud growth and electrical development. J. Atmos. Sci., 31, 16521661. 